\title{
Dosimetry for High Dose Applications
}

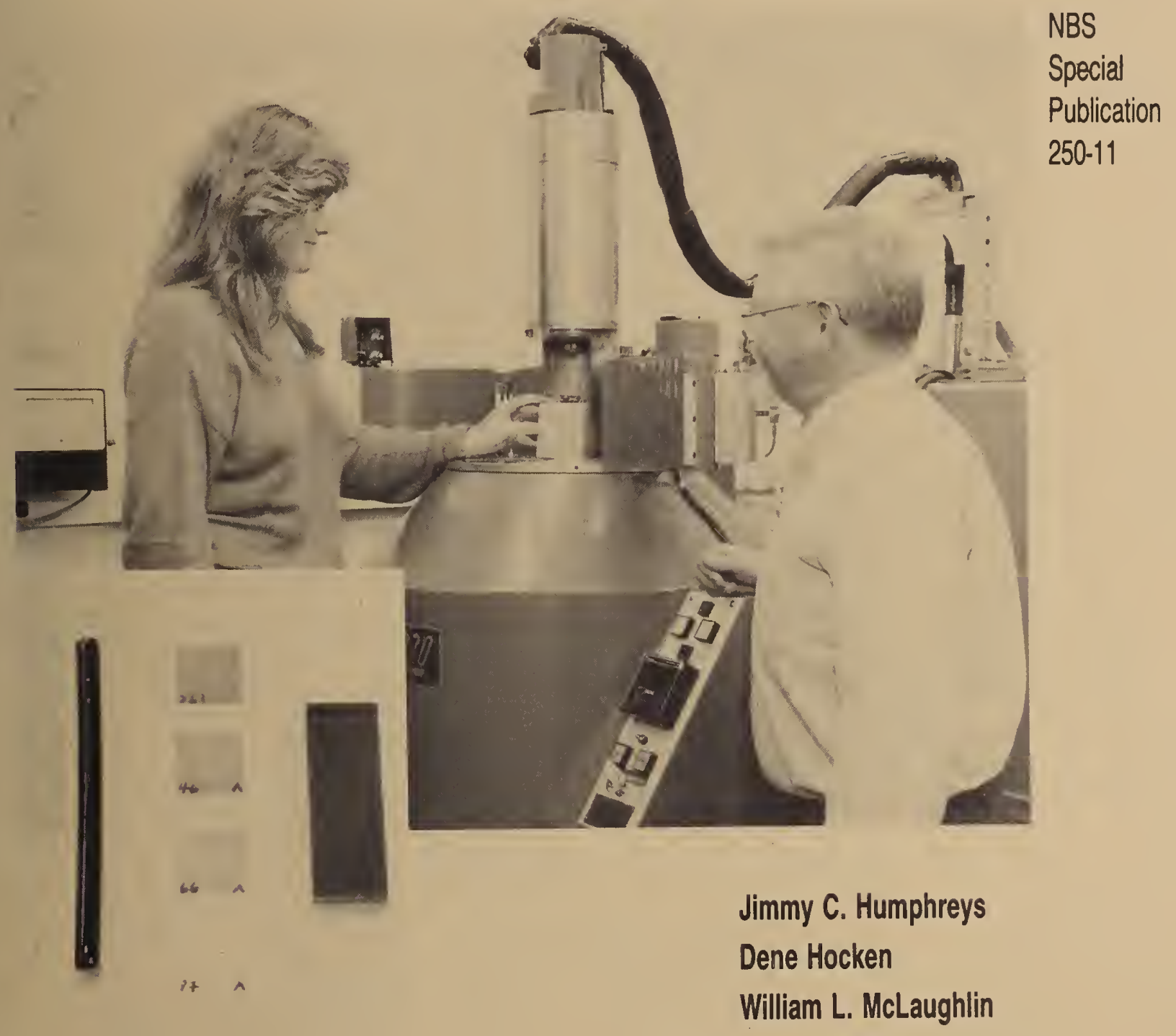

U.S. Department of Commerce

National Bureau of Standards 


\section{Center for Radiation Research}

The Center for Radiation Research is a major component of the National Measurement Laboratory in the National Bureau of Standards. The Center provides the Nation with standards and measurement services for ionizing radiation and for ultraviolet, visible, and infrared radiation; coordinates and furnishes essential support to the National Measurement Support System.for ionizing radiation; conducts research in radiation related fields to develop improved radiation measurement methodology; and generates, compiles, and critically evaluates data to meet major national needs. The Center consists of five Divisions and one Group.

\section{Atomic and Plasma Radiation Division}

Carries out basic theoretical and experimental research into the spectroscopic and radiative properties of atoms and highly ionized species; develops well-defined atomic radiation sources as radionetric or wavelength standards; develops new measurement techniques and methods for spectral analysis and plasma properties; and collects, compiles, and critically evaluates spectroscopic data. The Division consists of the following Groups:

\section{Radiation Physics Division}

provides the central national basis for the measurement of $f$ ar uitraviolet, soft $x-r a y$, and electron radiation; develops and disseminates radiation standards, measurement services, and data for for these radiations; conducts theoretical and experimental research with electron, laser, ultraviolet, and soft $x$-ray radiation for measurement applications; determines fundamental mechanisms of electron and photon interactions with matter; and develops advanced electron- and photon-based measurement techiques. The Division consists of the following Groups:

\section{Radiometric Physics Division}

Provides national measurement standards and support services for ultraviolet, visible, and infrared radiation; provides standards dissemination and measurement quality assurance services; conducts research in optical radiation, pyrometry, photometry, and quantum radiometry; and develops spectroradiometric and spectrophotometric standards and calibration procedures. The Division consists of the following Groups:

\section{Radiation Source and Instrumentation Division}

Develops, operates, and improves major NBS radiation facilities including the electron Linac and race track microtron; develops, designs, and builds electronic and mechanical instrumentation for radiation programs and facilities; provides national leadership in the standardization of nuclear instrument ation; and develops new competence in radiation sources and instrumentation. The Division consists of the following Groups:

\section{lonizing Radiation Division}

Provides primary national standards, measurement services, and basic data for applications of ionizing radiation; develops new methods of chemical and physical dosimetry; conducts theoretical and experimental research on the fundamental physical and chemical interactions of ionizing radiation with matter; provides essential standards and measurement support services to the National Measurement Support System for Ionizing Radiation; and develops and operates radiation sources needed to provide primary radiation standards, fields, and well-characterized beams of radiation for research on radiation interactions and for development of measurement methods. The Division consists of the following office and Groups:

\section{Nuclear Physics Group}

Engages in forefront research in nuclear and elementary particle physics; performs highly accurate measurements and theoretical analyses which probe the structure of nuclear matter; and improves the quant it ative understanding of physical processes that underlie measurement science. 


\section{NBS MEASUREMENT SERVICES: DOSIMETRY FOR HIGH DOSE APPLICATIONS}

Jimmy C. Humphreys

Dene Hocken

William L. McLaughlin

Center for Radiation Research

National Measurement Laboratory

National Bureau of Standards

Gaithersburg, MD 20899

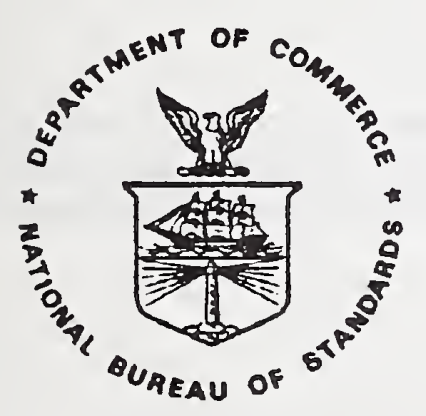

U.S. DEPARTMENT OF COMMERCE, C. William Verity, Secretary NATIONAL BUREAU OF STANDARDS, Ernest Ambler, Director Issued March 1988 
Library of Congress Catalog Card Number: 88-600506

National Bureau of Standards Special Publication 250-11

Natl. Bur. Stand. (U.S.), Spec. Publ. 250-11, 49 pages (Mar. 1988)

CODEN: XNBSAV

Certain commercial equipment, instruments, or materials are identified in this paper in order to adequately specify the experimental procedure. Such identification does not imply recommendation or endorsement by the National Bureau of Standards, nor does it imply that the materials or equipment identified are necessarily the best available for the purpose.

\section{U.S. GOVERNMENT PRINTING OFFICE}

WASHINGTON: 1988

For sale by the Superintendent of Documents, U.S. Government Printing Office, Washington, DC 20402-9325 


\section{PREFACE}

The calibration and related measurement services of the National Bureau of Standards are intended to assist the makers and users of precision measuring instruments in achieving the highest possible levels of accuracy, quality, and productivity. NBS offers over 300 different calibration, special test, and measurement assurance services. These services allow customers to directly link their measurement systems to measurement systems and standards maintained by NBS. These services are offered to the public and private organizations alike. They are described in NBS Special Publication (SP) 250, NBS Calibration Services Users Guide.

The Users Guide is being supplemented by a number of special publications (designated as the "SP 250 Series") that provide a detailed description of the important features of specific NBS calibration services. These documents provide a description of the: (1) specifications for the service; (2) design philosophy and theory; (3) NBS measurement system; (4) NBS operational procedures; (5) assessment of measurement uncertainty including random and systematic errors and an error budget; and (6) internal quality control procedures used by NBS. These documents will present more detail than can be given in an NBS calibration report, or than is generally allowed in articles in scientific journals. In the past NBS has published such information in a variety of ways. This series will help make this type of information more readily available to the user.

This document (SP 250-11), NBS Measurement Services: Dosimetry for High-Dose Applications, by J. C. Humphreys, D. Hocken, and W. L. McLaughlin, is the eleventh to be published in this new series of special publications. It covers the dosimetry services available to users of intense radiation fields, in particular large qamma-ray sources and electron accelerators up to about $10 \mathrm{MeV}$. These are: dosimeter irradiation services (see test numbers 49010S, 49040S, and $49041 \mathrm{~S}$ in the SP 250 Users Guide); dosimeter calibrations (49020S and 49030S); and measurements of dosimeter characteristics (49050S).

Inquiries concerning the technical content of this document or the specifications for these services should be directed to the authors or one of the technical contacts cited in SP 250.

The Center for Radiation Research (CRR) is in the process of publishing 21 documents in this SP 250 series, covering all of the calibration services offered by CRR. A complete listing of these documents $c$ an be found inside the back cover.

NBS would welcome suggestions on how publications such as these might be made more useful. Suggestions are also welcome concerning the need for new calibration services, special tests, and measurement assurance programs.

Joe D. Simmons

Acting Chief

Measurement Services
Chris E. Kuyatt

Director

Center for Radiation Research 


\section{ABSTRACT}

This document describes calibration services available at the National Bureau of Standards for the standardization of high absorbed dose measurements of ionizing radiation. The areas of application of such measurements include medical product sterilization, electronic device radiation hardness testing and food processing. Detailed descriptions of the NBS dosimetry procedures and uncertainty assessments are given. Measurement assurance program techniques are discussed.

Key words: Dosimeter calibration, ionizing radiation, irradiation facilities, measurement assurance program, uncertainties. 
TABLE OF CONTENTS

1. Description of Service

2. Design Philosophy and Theory

3. Description of System . . . . . . . . . . . . . . . . . . 3

$3.1{ }^{60}$ Co Irradiation Facilities . . . . . . . . . . . . . . . 3

3.2 Transfer Standard Dosimeters. . . . . . . . . . . . . . 9

3.3 Spectrophotometer . . . . . . . . . . . . . . . . . . 9

3.4 Thickness Gauge . . . . . . . . . . . . . . . . . . . 9

4. Operating Procedures . . . . . . . . . . . . . . . . . . . 9

4.1 Internal Dosimeter Calibration . . . . . . . . . . . . . . 9

4.2 Irradiation of Customer Dosimeters . . . . . . . . . . . . . . . . 14

4.3 Application of Transfer Dosimeters . . . . . . . . . . . . . . . 18

4.4 Analysis of Dosimeters . . . . . . . . . . . . . . . . . . 20

5. Assessment of Uncertainties. . . . . . . . . . . . . . . . . . . 20

6. Internal Quality Control . . . . . . . . . . . . . . . 27

7. Safety . . . . . . . . . . . . . . . . . . . . . . . . 29

References .. . . . . . . . . . . . . . . . . . . . . . 30

Appendix A: A Report of Calibration of Irradiation of Customer's Dosimeters

Appendix B: Instructions to Customer for Irradiation of Transfer Dosimeters

Appendix C: A Report of Calibration of Results of Transfer Dosmeter Measurements 
Table $1{ }^{60}$ Co Decay Corrections Factors $\left(C_{d}\right)$. . . . . . . . . . . . 13

Table 2 Various Dosimeters Types . . . . . . . . . . . . . . . . . 17

Table 3 Uncertainties in Absorbed Dose Values for Irradiations with Pool Source. . . . . . . . . . . . . . . . . . . . 21

Table 4 Uncertainties in Absorbed Dose Values for Irradiations with Gammacell 220 . . . . . . . . . . . . . . . . . . 24

Table 5 Uncertainties in Absorbed Dose Values for Irradiations with Vertical Beam Source. . . . . . . . . . . . . . . . 25

Table 6 Uncertainties in Absorbed Dose Values Employing Transfer Standard Dosimeters . . . . . . . . . . . . . . . . 26 
Fig. 1. Photograph of model of NBS 60 Co Pool Source........ . . . 4

Fig. 2. Schematic drawing of Gammacell 220 self-shielded 60 Co irradiator in the chamber load position . . . . . . . . . . . . . . 6

Fig. 3. Schematic Drawing of Gammacell 220 irradiator in the irradiate position... . . . . . . . . . . . . . . . 7

Fig. 4. Schematic drawing of teletherapy type shielded-head 60 Co irradiator . . . . . . . . . . . . . . . . . 8

Fig. 5. Examples of optical spectral scans of unirradiated radiochromic dye film dosimeter. . . . . . . . . . . . . . . . . . . . 11

Fig. 6. Typical $605 \mathrm{~nm}$ calibration curve for radiochromic dye film dosimeters . . . . . . . . . . . . . . . . . . . 15

Fig. 7. Typical 510nm calibration curve for radiochromic dye film dosimeters . . . . . . . . . . . . . . . . . . . 16

Fig. 8. Dependence of response of radiochromic dye film dosimeters on temperature during irradiation . . . . . . . . . . . . . . . 19 



\section{NATIONAL BUREAU OF STANDARDS \\ MEASUREMENT SERVICES: \\ DOSIMETRY FOR HIGH-DOSE APPLICATIONS}

\section{Description of Service}

1.1 The National Bureau of Standards, Ionizing Radiation Division, provides dosimetry services for individual users of intense radiation fields, in particular, large gamma-ray sources and electron accelerators up to approximately $10 \mathrm{MeV}$. These services include the administering of known absorbed doses of ionizing photons to customer-supplied dosimeters (such as solid radiochromic or liquid chemical types) or test samples that are sent to NBS (schedule 49010S, previously 8.6A), [1] "where they are packaged in appropriate conditions of electron equilibrium and are then irradiated in the NBS standard ${ }^{60} \mathrm{Co}$ calibration facility to specific agreed-upon absorbed dose values in the nominal "high-dose" ranges of $10-10^{6}$ grays $\left(10^{3}-10^{8}\right.$ rads). The dosimeters may either be spectrophotometrically read and evaluated by NBS (schedule 49040S and 49041S, previously 8.6D and 8.6E) or sent back to the customer for analysis and evaluation.

1.2 Another service (schedules $49020 \mathrm{~S}$ and 49030S, previously $8.6 \mathrm{~B}$ and 8.6C) consists of supplying to customers calibrated transfer dosimeters (radiochromic dye type), packaged in appropriate equilibrium material, such as polystyrene or aluminum, for irradiation and subsequent readout and absorbed dose interpretation. These dosimeters are provided in sealed packages and sent to the customer for irradiation to nominal agreed-upon absorbed dose levels in a prescribed geometrical arrangement. The unopened packaged dosimeters are then returned to NBS to be read and evaluated. The absorbed dose range that is suitable for the radiochromic dosimeters is 1 to $50 \mathrm{kGy}(0.1$ to 5 Mrad) in water, silicon, aluminum, graphite, or certain plastics.

1.3 Finally, NBS offers special measurement services (schedule 49050S, previously $8.6 \mathrm{~F}$ ) such as the determination of temperature dependence, absorbed dose-rate dependence or reproducibility of dosimeter response, and measurement of detailed absorbed dose distributions in specific irradiation geometries and in selected absorbing materials. The absorbed dose distribution measurements can include absorbed dose profiles in heterogeneous absorbers and at surfaces and interfaces of different substances. Such information is important in research leading to the commissioning of a radiation process, and in measurement assurance that provides quality control of a given radiation treatment.

"Numbers in square brackets indicate references, to be found at the end of the text. 


\section{Design Philosophy and Theory}

2.1 There is a need for the standardization of high-absorbed-dose measurements used in the radiation processing industry in order to provide measurement assurance and traceability to national standards. Some areas of applications of radiation processing include medical product sterilization, polymer modification, hardness testing of electronic devices, and processing of food or food packaging materials.

2.2 The principal sources of radiation employed in processing are ${ }^{60}$ Co gamma rays and electron beams from accelerators. Other photon sources used to a much more limited extent are ${ }^{137} \mathrm{Cs}$ gamma rays and high-energy bremsstrahlung $\mathrm{x}$ rays. The absorbed-dose range of interest is from about $100 \mathrm{~Gy}$ ( $10 \mathrm{krad}$ ) to $50 \mathrm{kGy}$ ( 5 Mrad), depending on the application. The upper limit of electron beam energy is assumed to be about $10 \mathrm{MeV}$ to avoid the possibility of nuclear activation. The lower practical energy limit for electron beams is determined by product thickness and may be as low as $0.1 \mathrm{MeV}$ for the curing of thin coatings.

2.3 The physical quantity of interest is absorbed dose in a material. Absorbed dose is defined as energy absorbed per unit mass of a specific material; the units are

$$
1 \text { gray }(G y)=1 \text { joule per kilogram }\left(\mathrm{J} \mathrm{kg}^{-1}\right)=100 \mathrm{rad}
$$

Generally, the materials of interest in radiation processing are made up of low atomic-number elements such as carbon, hydrogen, oxygen, and nitrogen. Such materials are quite well approximated by water. Thus, water is usually used as the reference material in which the absorbed dose measurement is specified. An exception is for electronic device hardness testing in which the reference material generally is silicon.

2.4 The primary standard employed in this service is a radiation-absorption calorimeter. When a material is irradiated by a photon or electron source, the energy absorbed results in a temperature increase. The absorbed dose, D, in the material is given by

$$
D=E / m=c \Delta T
$$

where $\mathrm{E}=$ energy absorbed in the material,

$\mathrm{m}=$ mass of the material,

$c=$ specific heat of the material,

$\Delta \mathrm{T}=$ temperature increase of the material.

The absorbed dose rate from a radiation source may be determined in a similar manner by measuring the rate of temperature increase in an irradiated material. For a radionuclide source, the absorbed dose rate at some other time (different from the actual measurement time) may be calculated by using the well-known exponential decay rate (i.e., the half life). 
2.5 The absorbed-dose rates encountered in radiation processing can cover an extremely wide range. For ${ }^{60}$ Co sources, the rates may be as low as a few grays per minute; for electron beams, rates as high as $10^{10}$ grays per second are not uncommon. Therefore, practical routine dosimeters must either be calibrated at approximately the same absorbed-dose rate employed in processing or their response must be known to be essentially absorbed dose-rate independent.

2.6 The principal dosimetry need in radiation processing is the provision for calibration of the response of routine dosimeters (i.e., a physical change such as optical absorbance) as a function of absorbed dose in water over the energy and absorbed dose-rate range of interest. However, if for the specific radiation type (i.e., photons or electron beams), the energy and absorbed dose rate requirements cannot be met by the calibration facility, then the response of the routine dosimeters must be shown to be independent of those qualities over the range of interest.

2.7 An important requirement for performing proper calibration measurements is that "electron equilibrium" conditions should exist during irradiation [2]. Such conditions exist when the number and energy of secondary electrons (generated by the primary photons) entering the volume of interest are equal to the number and energy of secondary electrons leaving the volume. Electron equilibrium may be established by surrounding the dosimeter with an appropriate thickness of material. For example, $5 \mathrm{~mm}$ of polystyrene is commonly used for ${ }^{60} \mathrm{Co}$ irradiations and the absorbed dose in polystyrene is usually converted to absorbed dose in water. If the absorbed dose is to be specified in silicon, then an appropriate material thickness for surrounding the dosimeter would be $2.2 \mathrm{~mm}$ of aluminum.

\section{Description of System}

$3.1{ }^{60} \mathrm{Co}$ irradiation facilities. NBS employs three ${ }^{60} \mathrm{Co}$ gamma-ray irradiators for its high-dose calibration service.

3.1.1 The pool-type source consists of a stationary annular array of twelve source rods of about 5 kiloCurie ( $\mathrm{kCi}$ ) total activity. It is situated at the bottom of a twelve-foot deep tank filled with water for shielding and personnel protection. The source array is shown in Figure 1. Irradiation of dosimeters is done manually by inserting into the source array a watertight stainlesssteel can with an inside diameter of $8 \mathrm{~cm}$. The volume of uniform absorbed dose rate is about $4 \mathrm{~cm}$ in diameter by $4 \mathrm{~cm}$ high, centered at $6.5 \mathrm{~cm}$ above the inside bottom of the can on the central axis. The absorbed dose rate of this source has been previously determined by an adiabatic graphite spherical calorimeter and a graphite ionization chamber of identical dimensions to an overall uncertainty estimated to be about \pm 0.48 at a 998 confidence level [3]. Periodic verification checks of the absorbed dose rate is done annually by means of reference transfer dosimeters in collaboration with the National Physical Laboratory (NPL) of the U.K. The absorbed dose rate in water in May 1986 was $0.076 \mathrm{kGy} \cdot \mathrm{min}^{-1}$. A complete discussion is given in reference [3] of the sources of the uncertainties in the absorbed dose rate of this ${ }^{60} \mathrm{Co}$ facility. The effect of these uncertainties on absorbed dose values assigned to irradiations performed in this facility is discussed in section 5. 


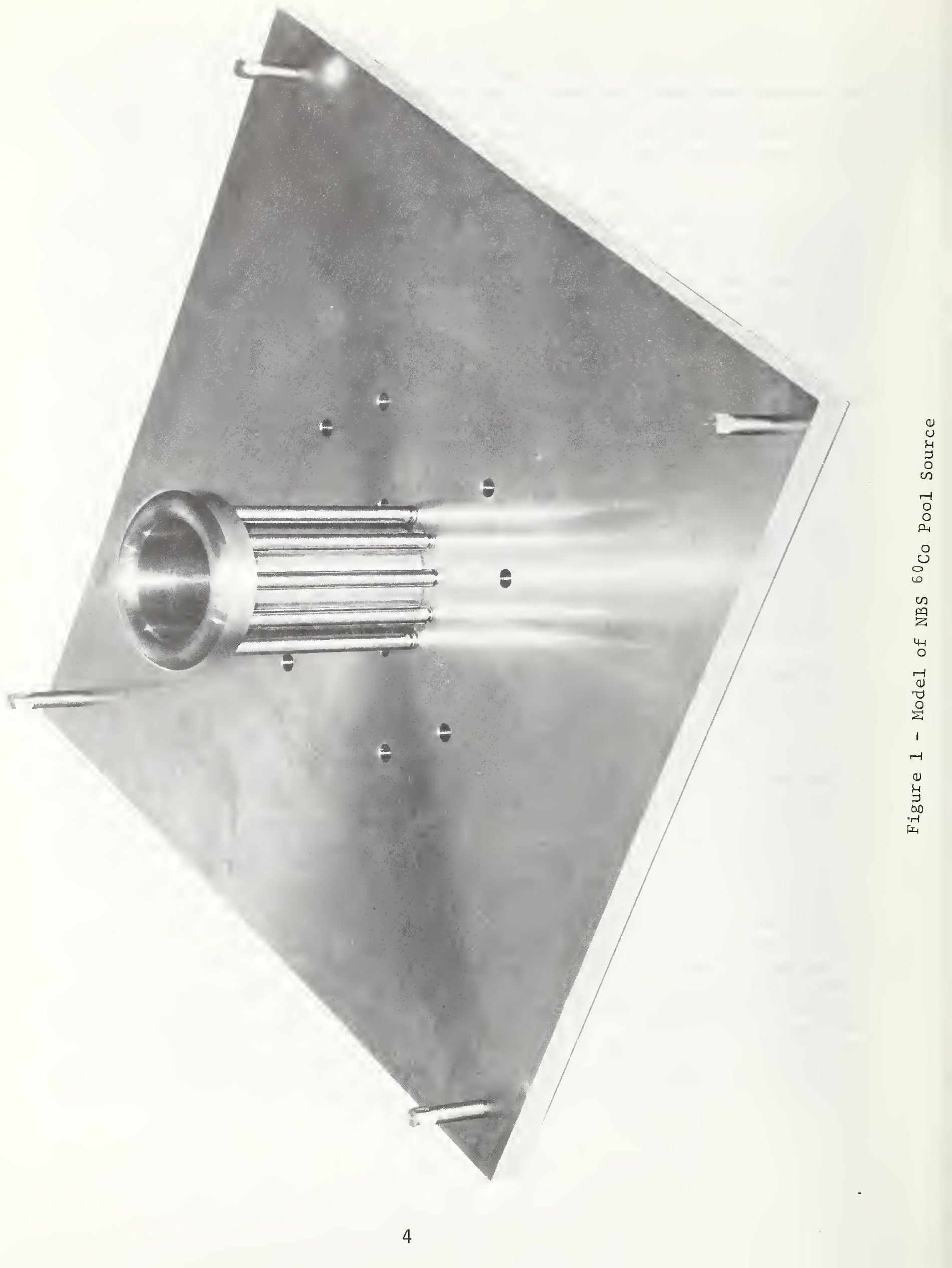


3.1.2 The Gammacell 220 irradiator, illustrated in Figures 2 and 3 is a commercially supplied unit (manufactured by AECL of Canada), with $24{ }^{60} \mathrm{Co}$ source rods of about $20 \mathrm{kCi}$ total activity in a stationary annular array. The source rods are located inside a massive lead-steel shielding structure that provides personnel protection. A motorized "drawer" assembly, consisting of an open irradiation chamber and shielding plugs above and below, can be moved up and down through the cylindrical source array. Dosimeters are placed in the irradiation chamber (with the drawer up), then the drawer is lowered so that the chamber is positioned reproducibly in the geometrical center of the source array. Control of the drawer is by means of a preset timer so that irradiations may be performed automatically. The irradiation chamber has inside dimensions of $15 \mathrm{~cm}$ diameter by $20 \mathrm{~cm}$ high. The absorbed-dose rate in water in May 1986 was $0.21 \mathrm{kGy} \cdot \mathrm{min}^{-1}$. This rate was calibrated by means of potassium dichromate reference transfer dosimeters from NPL in the U.K. and verified by NBS radiochromic dye film transfer dosimeters on an annual basis. The estimated overall uncertainty in this rate is about $\pm 3 \%$ at a $95 \%$ confidence level [4, 5]. Discussion of uncertainties associated with absorbed dose values for dosimeters irradiated with this unit is given in Section 5.

Significant radiation heating of dosimeters can occur during irradiation in this unit, so an active cooling system consisting of a flow of chilled dry compressed air is provided to maintain the sample temperature at $24^{\circ} \mathrm{C}$.

3.1.3 The vertical-beam ${ }^{60} \mathrm{Co}$ source consists of a single capsule containing about $4 \mathrm{kCi}$, housed in a shielding head with a shutter and collimator assembly, as shown in Figure 4. The dosimeters to be irradiated are placed at a measured distance from the source, the shutter assembly is opened, and the gamma rays emerge through the collimator unit into the shielded room. The irradiation time is controlled by an automatic preset timer on the shutter assembly.

The absorbed dose rate available from this unit varies as the inverse square of the distance from the source. At a distance of 1.5 meters, for May 1986, the absorbed dose rate in water was $0.17 \mathrm{~Gy} \cdot \mathrm{min}^{-1}$. This absorbed dose rate has been determined with an NBS standard graphite ionization chamber and is rechecked on an annual basis. The estimated overall uncertainty in this rate is about \pm 1.38 at a $95 \%$ confidence level. See Section 5 for detailed discussion of uncertainties in absorbed dose values for dosimeters irradiated with this unit. 


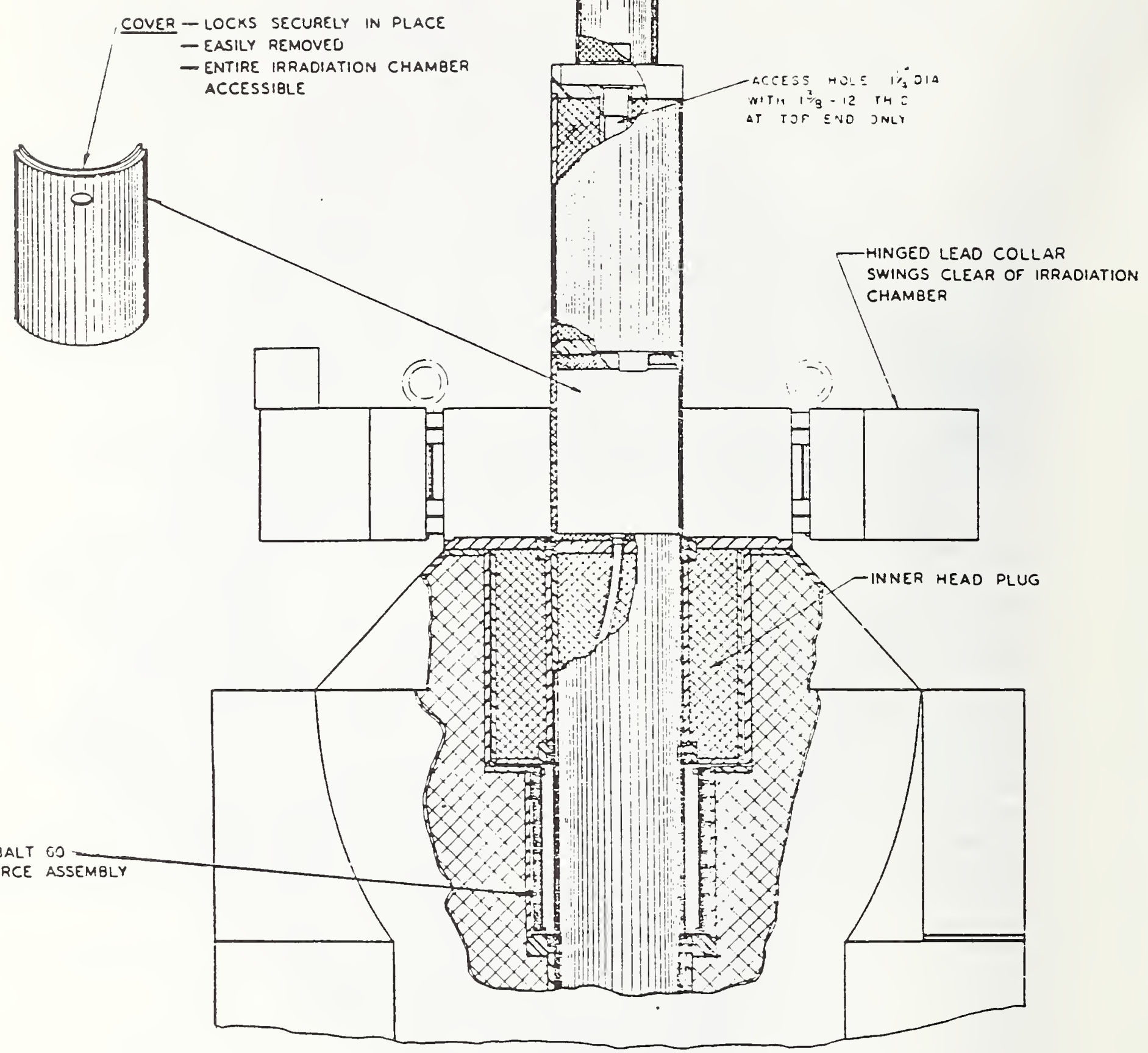

FRONT VIEW SHOWING DRAWER UP

Figure 2 - Schematic drawing of Gammacel1 220 self-shielded ${ }^{60} \mathrm{Co}$ irradiator in the chamber load position 


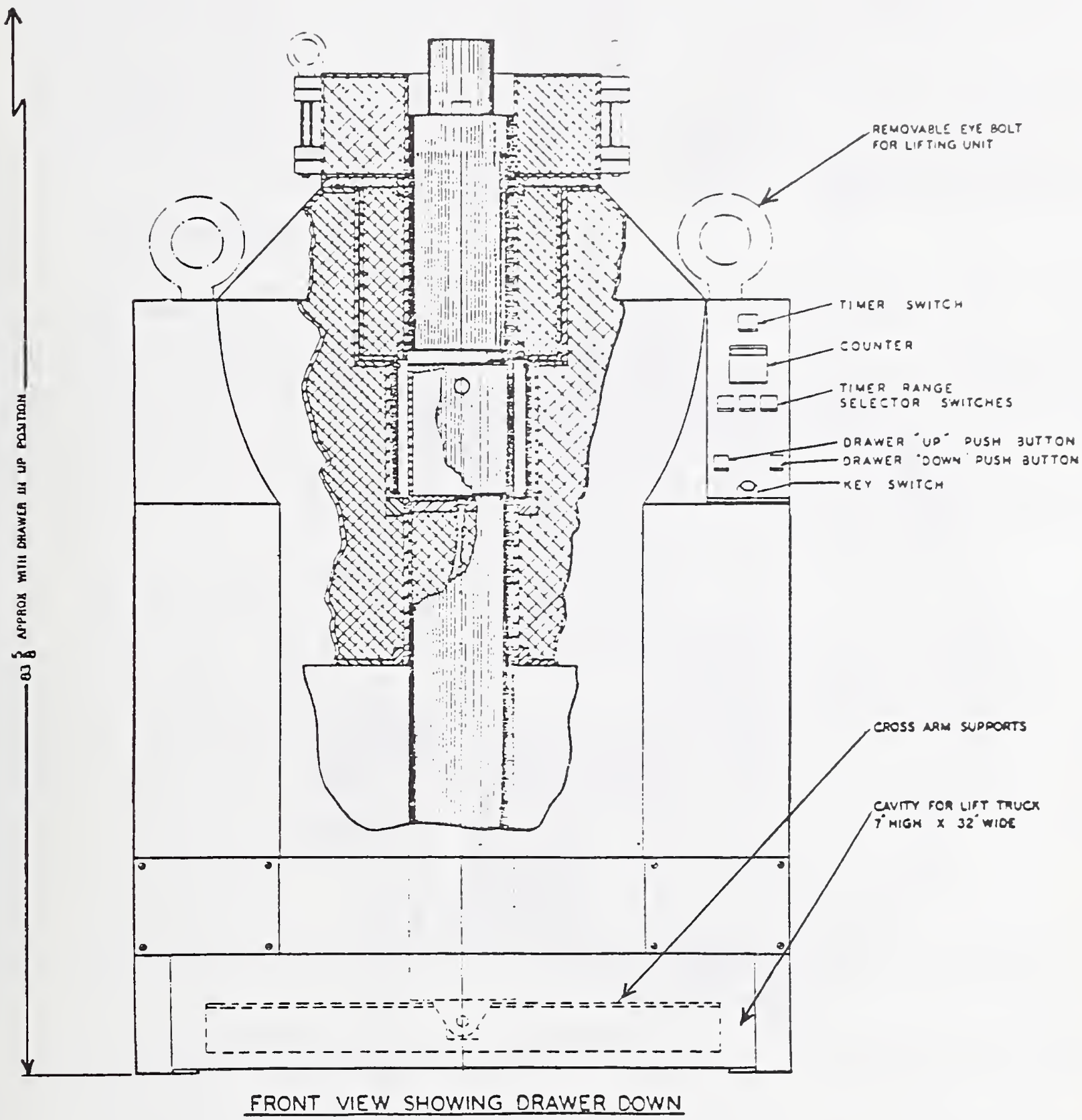

Figure 3 - Schematic Drawing of Gammacel1 220 irradiator in the irradiate position 


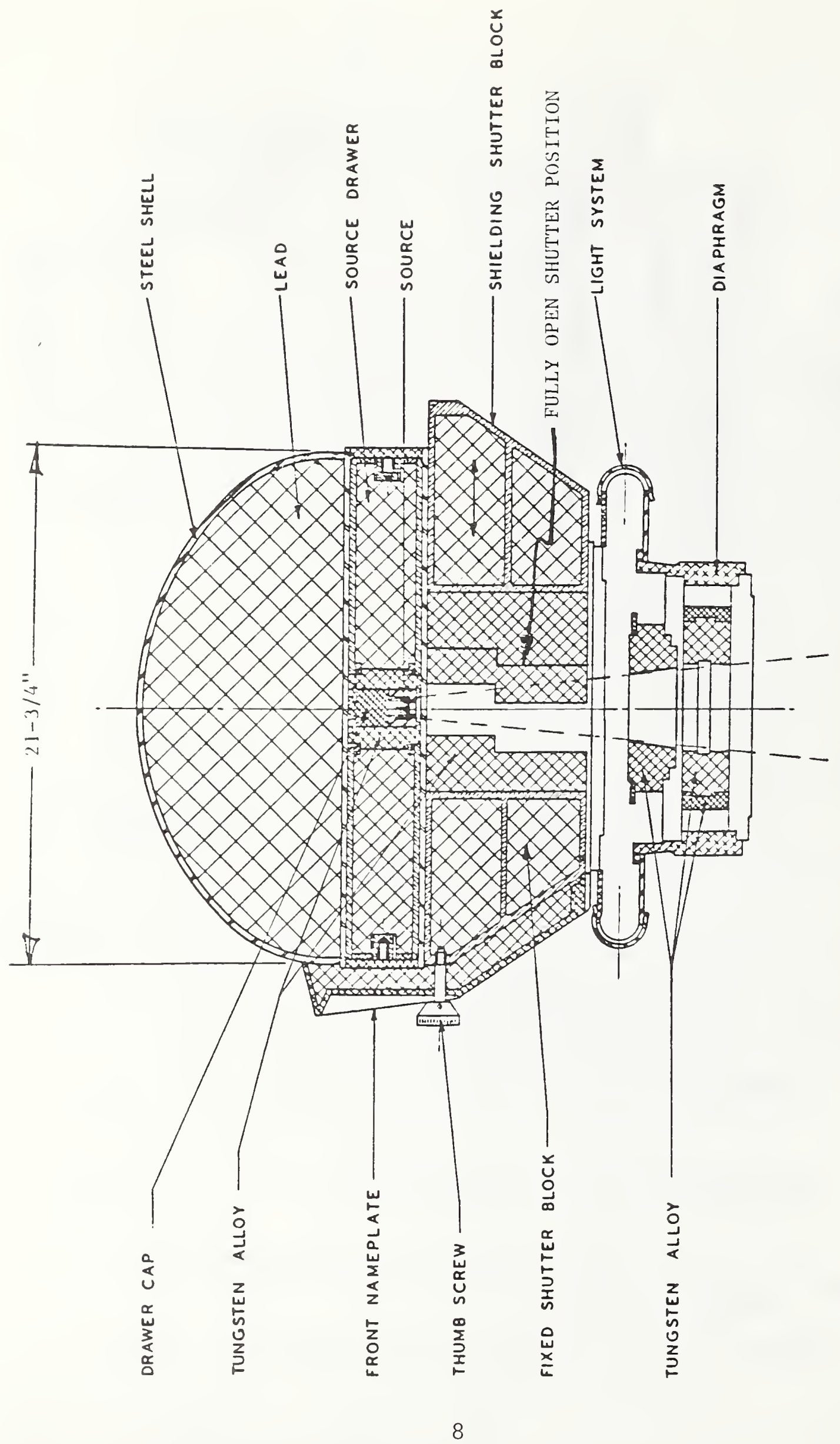

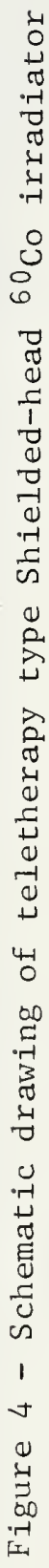




\subsection{Transfer Standard Dosimeters}

These dosimeters are radiochromic dye films, purchased in large batches from Far West Technology, that have been carefully and thoroughly characterized by NBS as to their response reproducibility, stability, absorbed dose-rate dependence, temperature and humidity dependence, and thickness. The dosimeters are type FWT-60-00, consisting of a nylon matrix incorporating an organic dye (leucocyanide of hexa-hydroxyethyl pararosaniline) in the form of a thin solid film, $1.0 \mathrm{~cm}$ square and $50 \mu \mathrm{m}$ thick [6]. A new batch is calibrated before being utilized as transfer dosimeters as described in the operating Procedures

\subsection{Spectrophotometer}

The primary instrument employed for the analysis (reading) of the radiochromic transfer dosimeters is a high-performance UV/VIS spectrophotometer. The instrument presently used is a Varian/Cary 219. This instrument has very low stray light characteristics so as to permit it to measure optical absorbance values of 3 or less with an uncertainty of less than 18 . The absorbance scale of the instrument is checked annually with a set of neutral density filters (SRM 930D). The wavelength scale is checked annually by means of emission lines of well known wavelength from a mercury discharge lamp. The wavelength scale must be within $0.2 \mathrm{~nm}$ of the specified value for the entire wavelength range (200 to $800 \mathrm{~nm}$ ).

\subsection{Thickness Gauge}

The radiochromic transfer dosimeters are normally $50 \mu \mathrm{m}$ thick and are measured with a thickness gauge to a resolution of $0.1 \mu \mathrm{m}$. The gauge is a Mitutoyo electronic Model DGS-E with a linear displacement transducer that has a special NBS developed digital display (not provided by the manufacturer). The calibration of the thickness scales is performed annually by use of a set of Brown \& Sharpe (Super-A Jo Blocks) metric gauge blocks.

\section{Operating Procedures}

\subsection{Internal Dosimeter Calibration}

The radiochromic dye film dosimeters described under 3.2 are calibrated by using the following procedures.

4.1.1 Upon receiving a new batch of dosimeters from the manufacturer, initial visual inspection is performed to detect any obvious flaws (fingerprints, water marks, etc.) that might make the batch unsuitable.

4.1.2 These dosimeters are sensitive to ultraviolet (UV) light and thus must be protected at all times from sunlight (even through windows), fluorescent lamps, or other sources. One effective method to achieve this is to filter laboratory fluorescent lamps with wrap-around filters made of a special UVabsorbing Mylar (trade named Llumar). Even with such filters, the dosimeters are only exposed to light during essential handling procedures, otherwise they are stored in the dark. 
4.1.3 Random dosimeter samples are taken from the batch to be calibrated. These samples are irradiated to specific absorbed dose levels and their responses are assumed to be indicative of the expected responses of the unirradiated dosimeters in the rest of that batch. The validity of this assumption has been verified experimentally for periods of 6 to 12 months. After 12 months a new calibration of the batch should be performed.

4.1.4 Handling of the individual dosimeters is done only with fine-tipped tweezers, touching only the outer $2 \mathrm{~mm}$ from the edges of the $1 \mathrm{~cm}$ square films, and, thus, avoiding scratches, fingerprints, etc., in the center where the analyzing light beam passes through. Small amounts of dust may be removed by gently wiping with lens tissue; however, any films that show obvious flaws such as fingerprints, dirt, optical imperfections, etc., are discarded.

4.1.5 The films are marked in a corner with a permanent ink pen so that consistent orientation may be maintained in all subsequent analysis procedures. The film is placed in a special black-anodized aluminum holder that masks the analyzing spectrophotometer light beam to a 6-mm square while holding the film perpendicular to the sample light beam in a reproducible position. A matching empty holder is placed in the reference light beam. With no films in either holder, the spectrophotometer may be properly balanced.

4.1.6 All films are irradiated to a low absorbed dose level of $1.0 \mathrm{kGy}$ before any optical analysis is performed. The slight coloration developed in the films as a result of this uniform low absorbed dose is proportional to the dye concentration in the films. Thus, optical absorbance readings of the films after this initial "pre-calibration" irradiation are made in order to eliminate the effects of variations in dye concentration and, therefore improve the precision of the response of the system. These "pre-calibration" irradiations are performed with the films packaged ten at a time under equilibrium conditions as described in 4.1.8.

4.1.7 Initially, each film is analyzed by a wavelength scan of the spectrophotometer from $5 \mathrm{~nm}$ above the primary absorption peak (at $605 \mathrm{~nm}$ ) to 5 $\mathrm{nm}$ below on an expanded absorbance scale (0.1A full scale, where A represents optical absorbance units). This scan will sometimes show optical interference fringes in the form of oscillations (see Fig. 5). If the peak-to-peak oscillations are greater than some specified value (0.001A), then the results are considered to be unsatisfactory. The holder and film are removed from the spectrophotometer and the film is rotated $90^{\circ}$ and then read again. If the oscillations are less than the specified value, then the film is considered acceptable. If all possible orientations are tried and the oscillations are still greater than the specified limit, then that film is rejected and another is selected to be tested in the same fashion. If the film reading is acceptable, then it is marked with permanent ink in the lower left corner with a unique code number. These initial readings are designated $A_{1}$. All subsequent readings of the film are done with this orientation. The wavelengths of analysis are $605 \mathrm{~nm}$ and $510 \mathrm{~nm}$, using a Varian/Cary 219 spectrophotometer with a spectral bandwidth of $3.5 \mathrm{~nm}$. 


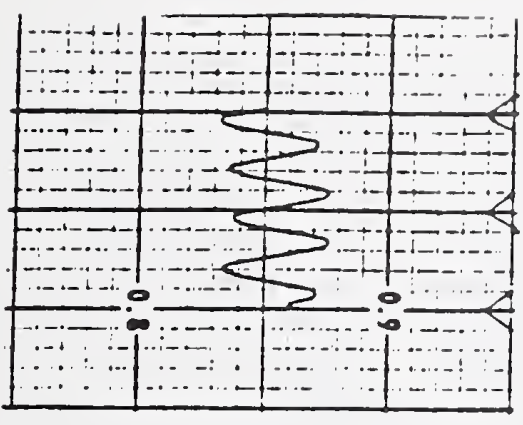

A.

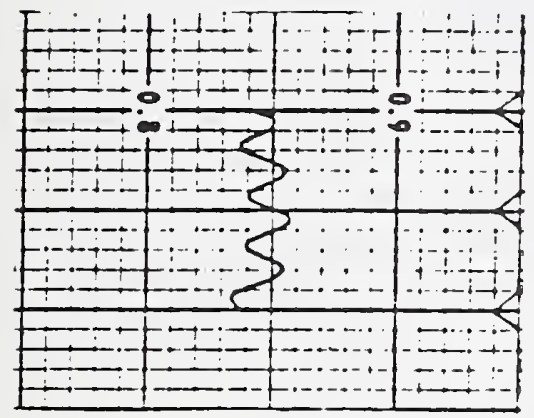

C.

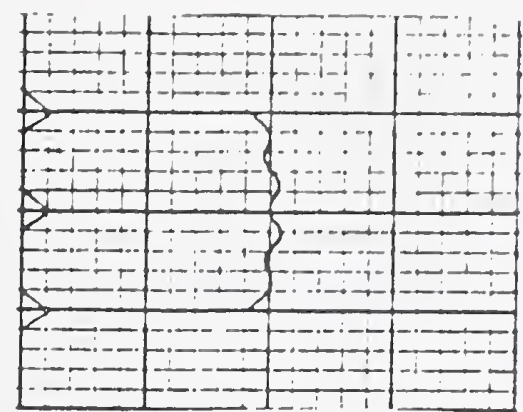

B.

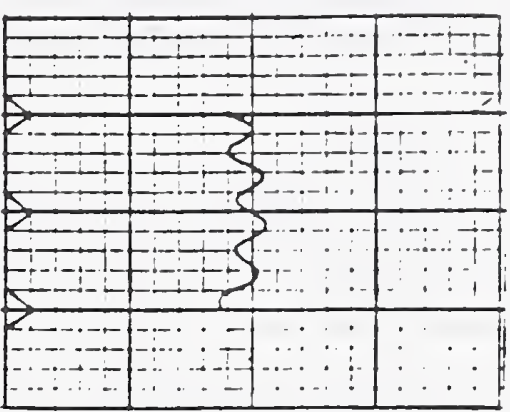

D.

FIGURE 5 Examples of FWT Ao scans, from $610 \mathrm{~nm}$ down to $600 \mathrm{~nm}$, showing various oscillations, for different orientations.

NOTE: Spectrophotometer settings:

RANGE: 0.1 ABS; S.B.W.: $3.5 \mathrm{~nm} ;$ PERIOD (sec): $1.0 ;$ CHART DISPLAY: $5 \mathrm{~nm} / \mathrm{cm} ; \mathrm{SCAN}$ RATE: $0.2 \mathrm{~nm} / \mathrm{sec}$.

A. First position: oscillations are too large and are not acceptable; film rotated $90^{\circ}$.

B. First rotation (second position): oscillations are very small and can be ignored; this is the most acceptable reading of all.

C. Second rotation (third position): oscillations, as in A, are not acceptable.

D. Third rotation (fourth position): oscillations are within specification; however, taking an average between the highest and lowest readings around $606 \mathrm{~nm}$ would be required for an accurate reading of low absorbance values of this film for this orientation. 
4.1.8 Before the calibration irradiations, the dosimeter films are stored at room temperature $\left(\approx 24^{\circ} \mathrm{C}\right)$ in a controlled humidity environment (within the range of 40 to $50 \%$ R.H.) for at least 24 hours [7]. After this period, the dosimeters are packaged in appropriate equilibrium build-up material. For the absorbed dose to be specified in water (or tissue), the equilibrium material used is polystyrene; for absorbed dose in silicon, the equilibrium material used is aluminum. The equilibrium material is in the form of 25 -mm square blocks, which are $5 \mathrm{~mm}$ thick for polystyrene and $2.2 \mathrm{~mm}$ thick for aluminum. There is a $12-\mathrm{mm}$ square cavity, $1 \mathrm{~mm}$ deep, in one block of each pair of blocks. A group of five dosimeters is stacked and placed in the cavity between the two blocks of the appropriate material then heat sealed in two pouches of $100 \mu \mathrm{m}$ thick polyethylene; an inner black layer for light protection, then an outer clear layer. After packaging, the dosimeters are ready for irradiation.

4.1.9 Most calibration irradiations are performed in the NBS ${ }^{60}$ Co pool source. Each dosimeter package is placed in a polystyrene foam holder fitted into the stainless steel can so as to locate it at the geometrical center of the source array. Irradiations are done by manually lowering the water-tight irradiation can (attached to a long handling pole) into the source array, noting the clock time, then removing the can (manually) at the end of the calculated irradiation time. The irradiation times for given absorbed doses are calculated before irradiations are started, based on previous verifications of the source absorbed dose rate and corrected for the exponential radioactive decay for ${ }^{60} \mathrm{Co}$ (based on a half-life of 5.27 years). Decay corrections are done every two days to provide a current absorbed dose rate. The decay correction factor is given by the equation:

$$
\dot{D}_{p}=\dot{D}_{\circ} e^{-\lambda t}
$$

where $\dot{\mathrm{D}}_{\mathrm{p}}=$ absorbed dose rate on the desired date,

$\dot{\mathrm{D}}_{\mathrm{o}}=$ absorbed dose rate on December 31 of the previous year,

$\lambda={ }^{60}$ Co decay constant, and

$t=$ number of days from December 31 of the previous year to the desired date.

Now,

$$
\lambda=\frac{0.693147}{\mathrm{~T}_{\frac{1}{2}}(\text { years }) \cdot 365.25 \text { days } / \text { year }}
$$

where $\mathrm{T}_{\frac{1}{2}}=$ half life for ${ }^{60} \mathrm{Co}=5.2714$ years.

Thus $\lambda=3.60006 \times 10^{-4} /$ day.

The decay correction factor $=C_{d}=e^{-\lambda t}$. Values for $C_{d}$ for various elapsed times are given in Table 1.

To use Table 1, determine the number of days since the previous December 31 (for which the absorbed dose rate was stated). Then multiply the correction factors from Table 1 that correspond to the total number of elapsed days. For example, if the absorbed dose rate on April 23 was desired, the number of elapsed days (for a non-leap year) would be 113 days. To determine the decay correction factor, look up the factor where the horizontal row for "100" 


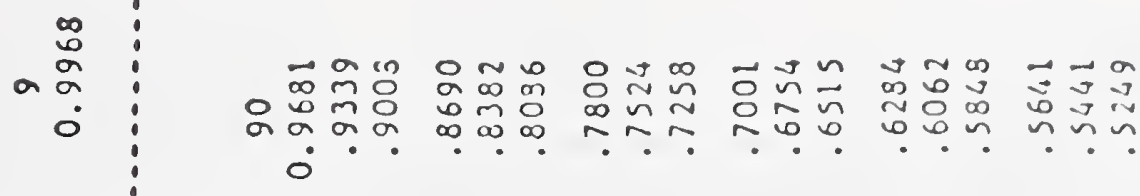

$$
\begin{aligned}
& \infty \stackrel{\circ}{\circ} \\
& \text { a }
\end{aligned}
$$

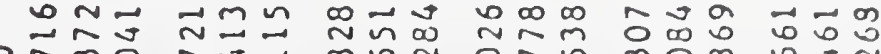

$$
\begin{aligned}
& \text { 응요 क } \\
& 0^{\circ} \\
& \neg D m N m g \text { N } \\
& \text { 응ํㅇ }
\end{aligned}
$$

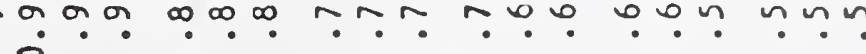


intersects the vertical "10" column corresponding to 110 days. This factor is 0.9611. The factor for "3", the remaining number of days, in the first row is 0.9989. Multiply these two factors to give the correction for 113 days: 0.9600. Multiply this factor by the absorbed dose rate for the previous December 31 to give the dose rate for April 23.

4.1.10 A typical calibration of a new batch would cover an absorbed-dose range of $1 \mathrm{kGy}$ to $50 \mathrm{kGy}$ with absorbed dose values of $2,5,10,15,20,30,40$ and $50 \mathrm{kGy}$.

4,1.11 After irradiation, the dosimeters are stored for approximately 24 hours to allow for complete development of the dye [7]. After this period, the final spectrophotometer readings (designated $\mathrm{A}_{2}$ ) are made, taking care that the same orientation of each film is used as for the initial $A_{1}$ readings.

4.1.12 Finally, the thickness of each dosimeter is read at three points across the film corresponding to where the spectrophotometer light beam passes through the dosimeter film. The mean value of these measurements is used as the film thickness.

4.1.13 All values of initial absorbance, $A_{1}$, final absorbance after irradiation, $A_{2}$, and thickness in $\mathrm{mm}, t$, for each dosimeter are recorded in a data book. The response of the dosimeter is given by, $R_{2}$

$$
\mathrm{R}_{2}=\frac{\mathrm{A}_{2}-\mathrm{A}_{1}}{\mathrm{t}}
$$

4.1.14 The mean $R_{2}$ for each group of five dosimeters irradiated together is plotted against the absorbed dose in the specified material. A curve is fitted through the data by means of a least squares regression method such as a polynomial fit. In general, the curve will be nonlinear, at least over certain portions of the absorbed dose range. Data for both wavelengths of analysis, $605 \mathrm{~nm}$ and $510 \mathrm{~nm}$, are used to generate separate calibration curves. See Figs. 6 and 7 for examples.

4.1.15 Dosimeters from the calibrated batch irradiated to some unknown absorbed dose are read according to the procedures of this section and the resulting absorbed dose is obtained from the calibration curves. The $605 \mathrm{~nm}$ calibration curve is used primarily to determine the absorbed dose value; the $510 \mathrm{~nm}$ results are used generally for redundancy to check on possible erroneous interpretation of the $605 \mathrm{~nm}$ results.

\subsection{Irradiation of Customer Dosimeters}

4.2.1 Various types of dosimeters may be submitted by customers for irradiation to various absorbed dose levels. Table 2 gives a brief listing of some typical dosimeter types and the applicable absorbed dose range for which they may be utilized; other types may also be processed.

4.2.2 The irradiation geometry used for these dosimeters depends on their size and shape. In general, if the requested absorbed dose is in water, then a container made of polystyrene with a $5-\mathrm{mm}$ wall thickness is used to hold the dosimeters in the proper location (i.e., the center of the source array for the 


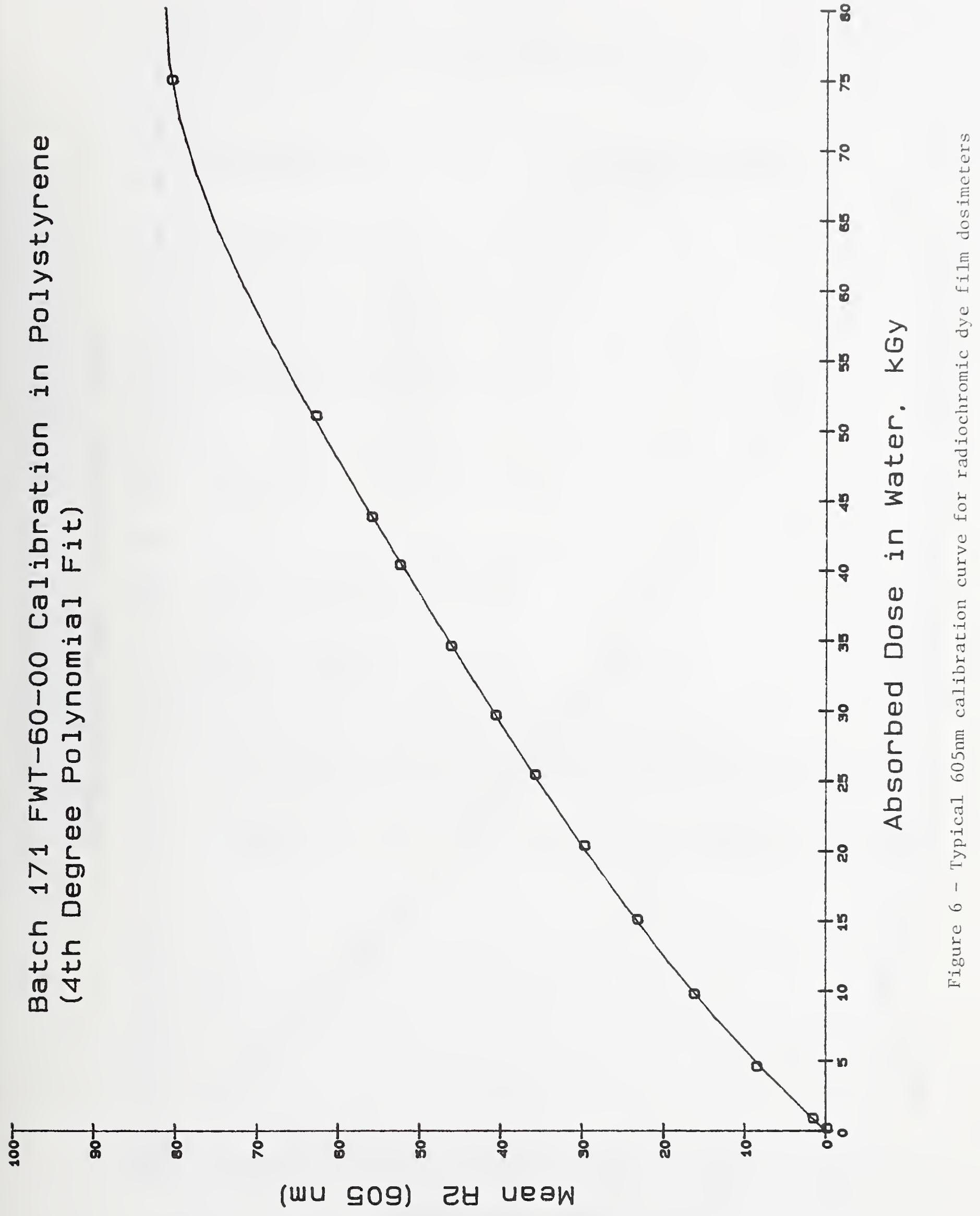




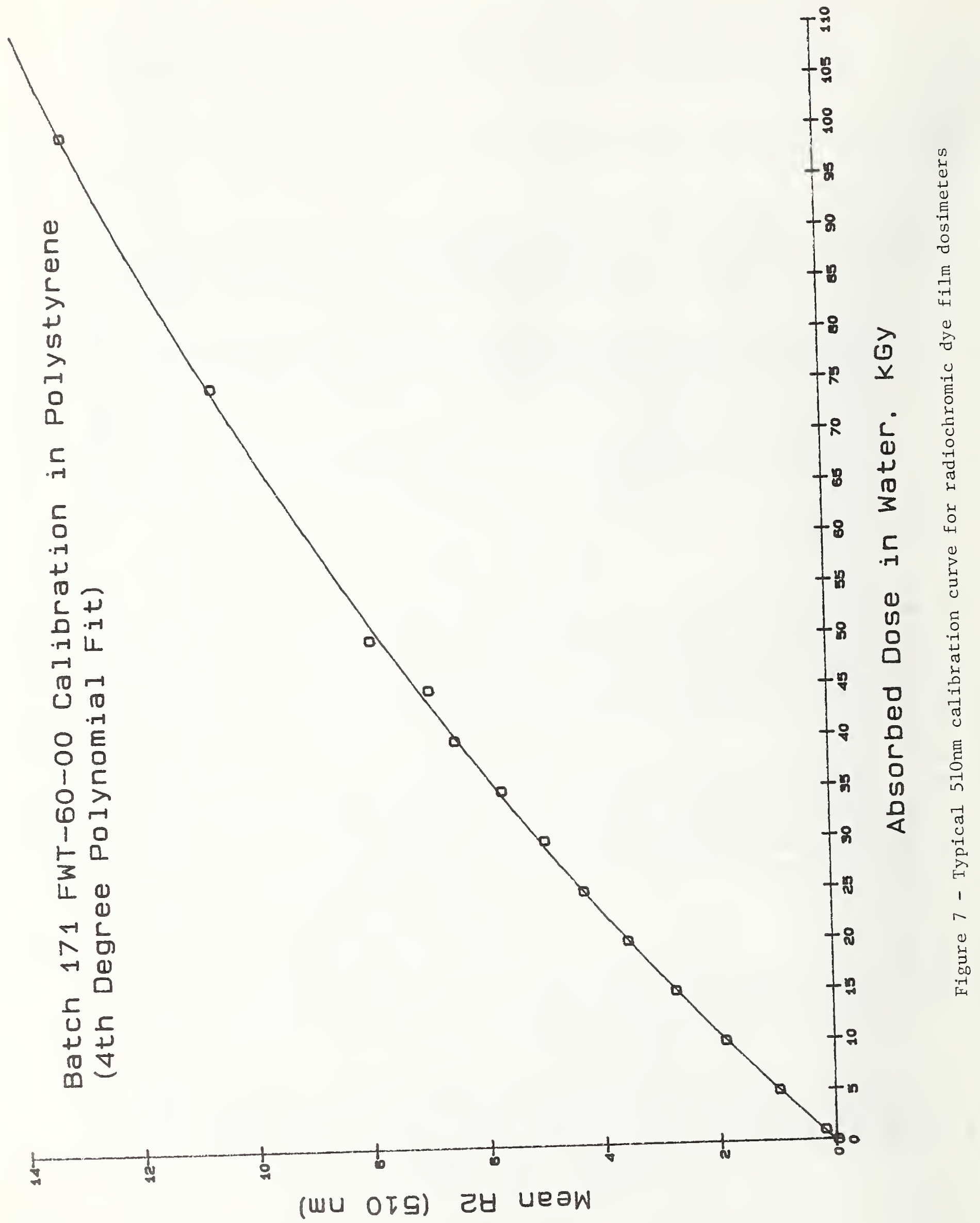




\section{VARIOUS DOSIMETER TYPES}

Dosimeter Type

FWT-60-00 dye filma

Harwell Red Perspex ${ }^{b}$

Harwell Amber Perspex

Harwell HX Perspex and Radix

clear PMMA ${ }^{b}$

Ceric-cerous sulfate solutions

Potassium and silver dichromate solutions

Fricke (ferrous sulfate) solution

Thermoluminescence dosimeters

( LiF, $\mathrm{CaF}_{2}$, etc.)

FWT Opti-chromic

(liquid in optical waveguide) $\frac{\text { Absorbed Dose Range }}{\mathrm{kGy} \text { in } \mathrm{H}_{2} \mathrm{O}}$

$1-50$

$5-50$

$1-20$

$3-100$

$0.3-100$

$1-50$

$0.01-0.4$

$0.01-1$

$0.02-10$

a The material of this film is primarily "Elvamide" nylon from DuPont. The radiochromic sensor is hexa-hydroxyethyl pararosaniline cyanide.

b "Perspex" and "Radix" are trade names for polymethyl methacrylate (PMMA). 
pool source) during irradiation. This container may be in the form of square blocks for FWT-60-00 thin dye films as used in the internal NBS calibration, or in the form of a cylindrical cup for Red Perspex or similar type dosimeters. These containers supply the material needed to provide electron equilibrium conditions during irradiation as previously discussed in 2.7. The Red Perspex dosimeters, for example, are about 3 -mm thick and a correction for self attenuation (of about $3 \%$ ) is necessary in order to specify the correct average absorbed dose rate in the dosimeters during calibration.

4.2.3 Upon completion of the irradiations requested by the customer, the dosimeters are returned promptly to him. In the case of fragile or unstable dosimeters, it is sometimes necessary to specify special shipping conditions. For example, because of instabilities following irradiation, Red Perspex dosimeters should be sent by express overnight mail service and should be protected from temperature extremes during that period. Aqueous chemical liquid dosimeter ampoules also require such precautions, as well as protection against breakage by careful packaging. After double checking the irradiation times and calculations of the absorbed-dose rates for that day, a Report of Calibration is prepared and sent to the customer specifying the absorbed doses given to his dosimeters (see Appendix A). The customer then formulates his own calibration curve based on the NBS absorbed-dose values and readout of the dosimeters with his own instrumentation.

\subsection{Application of Transfer Dosimeters}

4.3.1 When a customer requests dosimeters to be supplied for irradiation in his facility, the procedures of 4.1 .4 to 4.1 .8 are followed, using unirradiated dosimeters from a calibrated batch, i.e., reading initial absorbances, humidity conditioning, and then packaging the dosimeters.

4.3.2 The requested number of packaged unirradiated dosimeters (plus some controls) are sent to the customer, along with instructions on proper handling (e.g., do not open the packages), the proper absorbed dose level to be given (1 to $50 \mathrm{kGy}$ ), as well as reporting any special environmental conditions (e.g., elevated temperature during irradiation) (see Appendix B). If the temperature of the dosimeter package is expected to exceed $30^{\circ} \mathrm{C}$ during irradiation in the customer's facility, then the customer is requested to measure that temperature during the irradiation and provide NBS with those data (preferably as a function of time) in order that NBS can apply the proper correction factors to the dosimeter response (see Fig. 8).

4.3.3 When the irradiations are completed by the customer, he sends the dosimeter packages back to NBS. The packages are opened at NBS and the dosimeters read as soon as possible following the procedures of 4.1 .11 to 4.1.15. The results are corrected for elevated irradiation temperature, if required, and the results are compared to the nominal absorbed dose the customer reportedly gave the packages. Results are then supplied to the customer in the form of a Report of Calibration (see Appendix $C$ for an Example).

\subsection{Analysis of Dosimeters}

4.4.1 Reading of customers' dosimeters is done in a manner similar to that used for the internal calibration procedures detailed in 4.1. For FWT-60-00 


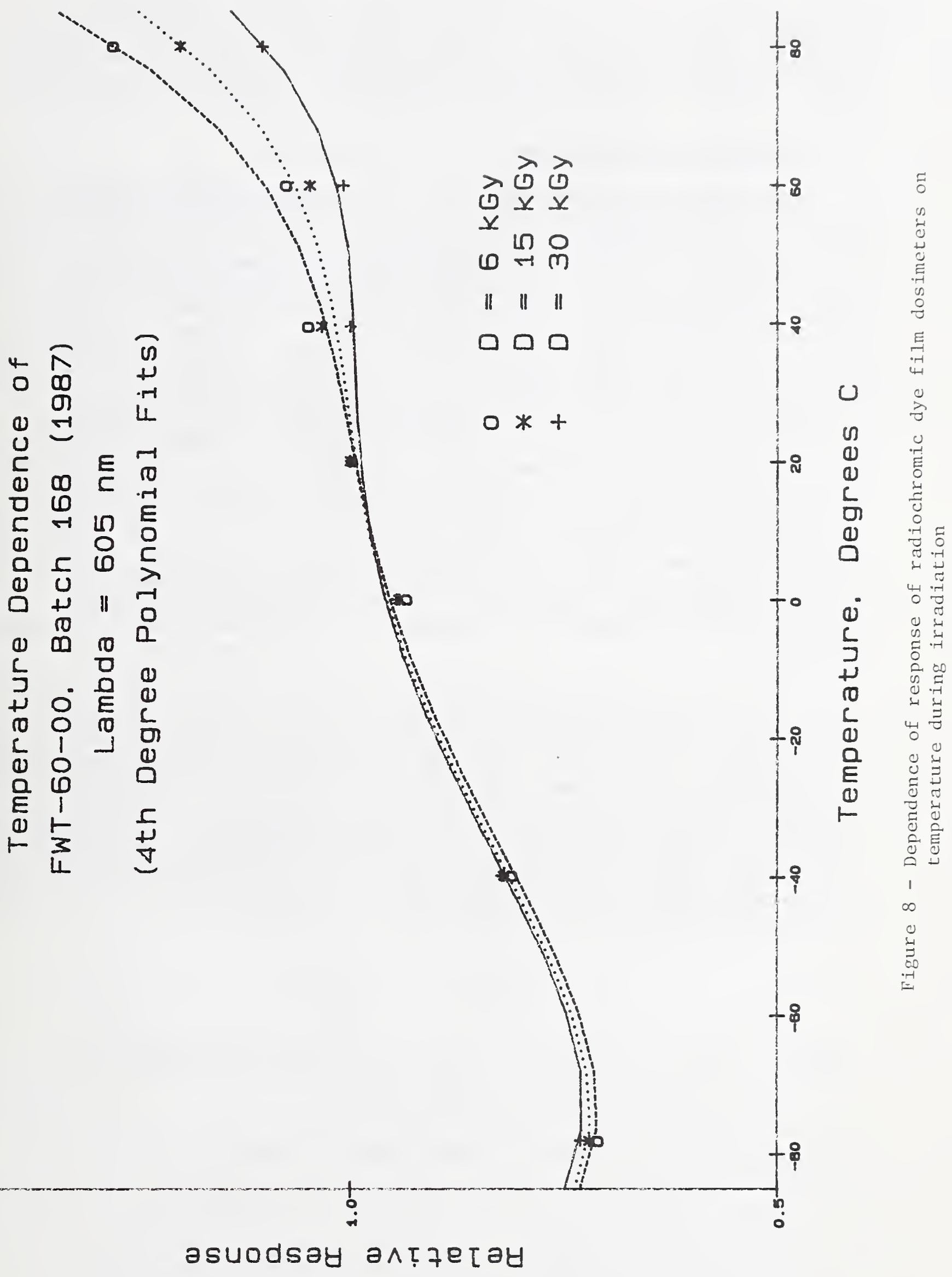


dye film dosimeters, the procedures are identical to those discussed in 4.1. For other types of dosimeters, the spectrophotometric analysis is tailored to meet their particular requirements. For example, Red Perspex dosimeters are read at only one wavelength $(640 \mathrm{~nm})$ and require a different holder than the FWT-type film.

\section{Assessment of Uncertainties}

5.1 The estimates of uncertainties for the absorbed dose values assigned to a given group of dosimeters irradiated together in the ${ }^{6}{ }^{\circ} \mathrm{Co}$ pool source are given in Table 3. The designation of the types of uncertainties (A and B) follows the recommendations of the BIPM Working Group on the Statement of Uncertainties $[8,9]$. Type $\mathrm{A}$ is the random component and is stated as an estimate of a sample standard deviation. These can be determined by standard (objective) statistical methods. Type B uncertainties are determined by "other methods", thus implying some element of subjective evaluation. Type B uncertainties may, in some cases, correspond roughly to "systematic" contributions, but this may not always be true. In line with the BIPM recommendations, the term "systematic" is avoided. Those recommendations also treat both types of uncertainties equally; that is, as being equivalent to "standard deviations". Thus, each type is combined separately in quadrature (i.e., the square root of the sum of the squares). An overall combined uncertainty is obtained by combining the two types once again in quadrature. Finally, a total uncertainty is obtained by multiplying a "safety" factor (such as 2 or 3 ); in this case the factor chosen was 3. For a normal population distribution this factor would correspond approximately to the statistical "Student's t-factor" at a 99\% confidence level and a sample size of about 14 (13 degrees of freedom), assuming that the combined uncertainties can actually be treated as a standard deviation.

5.2 The values of the uncertainties given in Table 3 for irradiations done with the pool source were determined from published literature or from experimental estimates. The published values usually are given for a $95 \%$ or $99 \%$ confidence level, so the values given in Table 3 are obtained by dividing the published values by two or three respectively so as to correspond to a "standard deviation" of one. The experimental estimates are usually the "maximum" expected range which would correspond roughly to a 998 confidence level. Thus, values for Table 3 were obtained by dividing these estimates by three. The values of uncertainties listed are stated in terms of percentages of the sample mean of the mesured quantity. This corresponds to a percentage of an estimated coefficient of variation [10] given by:

$$
\frac{100 \hat{\sigma}_{\bar{x}}}{\bar{x}}=\frac{100 \cdot s_{x}}{\bar{x} \sqrt{n}}
$$

where $\quad \hat{\sigma}_{\overline{\mathrm{x}}}=$ estimated standard deviation of the sample mean,

and $\quad \mathrm{s}_{\mathrm{x}}=$ computed sample standard deviation 
Table 3

UNCERTAINTIES IN ABSORBED DOSE VALUES

FOR IRRADIATIONS WITH POOL SOURCE

\section{Source of Uncertainty}

Graphite calorimeter/ion chamber measurement of pool source dose rate

Source decay, half life

Timing of irradiations

Conversion of dose rate: graphite to water, silicon, etc.

Attenuation corrections in equilibrium material

Effect of dosimeter positioning in irradiation can

Geometrical effects of equilibrium material on dose rate

Source decay correction for given date

Type A, Type B combined (in quadrature), separately

Combined (in quadrature)

TOTAL: $3 \mathrm{X}$ Combined
Type A ( 8$)$ Type B $\left(\frac{8}{8}\right)$ (random) (other)

0.14

0.01

0.23

0.30

0.03

0.25

1.00

0.02

0.34

1.05 
The sources of the uncertainties are as follows:

(1) The calorimeter/ion chamber measurements of the pool source absorbed dose rate were analyzed in reference [3] for all possible sources of error contributions such as core mass, electrical power, attenuation, and heating rate for the calorimeter, and air mass, current measurement, and collection efficiency for the ion chamber. All factors were combined in quadrature (square root of the sum of the squares) to give an overall value of 0.438 at a $99 \%$ confidence level. The value for Table 3 would be $0.43 \%$ divided by 3 or 0.148 .

(2) The uncertainty in the half life of ${ }^{60}$ Co was reported to be 5 parts out of 52,714 or 0.018 [11]. The level of confidence was not reported, so it was assumed to correspond to one standard deviation.

(3) The uncertainty in the timing of the irradiations was estimated to be a maximum of $5 \mathrm{~s}$ for the manual manipulation of the irradiation can into the source array. This would correspond roughly to a $99 \%$ confidence level, so dividing this time by 3 would give an uncertainty of $1.7 \mathrm{~s}$ for one standard deviation. For a $1 \mathrm{kGy}$ absorbed dose at the current absorbed dose rate, the irradiation time is about $750 \mathrm{~s}: 1.7 \mathrm{~s}$ is about 0.238 of this time.

(4) For the conversion of the absorbed dose rate of the source from one material (e.g., graphite) to another (e.g., water), the uncertainty in the ratio of mass energy absorption coefficients for photon spectra with significant scattered components down to about $100 \mathrm{keV}$ is estimated to be about $0.6 \%$ at a $95 \%$ confidence level [12]. Thus, the uncertainty value for one standard deviation would be 0.68 divided by 2 or 0.38 .

(5) For the correction for attenuation in the equilibrium buildup material surrounding the dosimeters, the uncertainty in the mass attenuation

coefficients down to $5 \mathrm{keV}$ is about $2 \%$ at a $95 \%$ confidence level [12], or $1 \%$ corresponding to one standard deviation. The correction factor is about $3 \%$, so the uncertainty in the factor would be about $0.03 \%$.

(6) The effect of variation of the location of the dosimeter package during irradiation can be estimated from isodose profiles that were determined previously. With a location imprecision of about $0.5 \mathrm{~cm}$, the uncertainty is estimated to be $0.5 \%$ at a $95 \%$ confidence level. The uncertainty value corresponding to one standard deviation would be 0.258 .

(7) The effects of different geometrical configurations for the equilibrium material (i.e., a cylinder compared to a slab) has been examined previously [13] and are estimated to contribute about a $3 \%$ uncertainty at a 998 confidence level. The uncertainty corresponding to one standard deviation would be $1 \%$.

(8) The uncertainty due to the calculation of the correction for source decay for a particular date can be estimated from the values in Table 1. Corrections are made every two days, so the maximum uncertainty would be about $0.07 \%$ (the difference between day 0 and day 2 values) at a 998 confidence level. The uncertainty corresponding to one standard deviation would be 0.028 .

5.3 For irradiations done with the Gammacell 220 irradiator, the estimated uncertainties for absorbed dose values are given in Table 4. Most of the uncertainties are the same as for the pool source irradiations shown in Table 3 with some notable exceptions:

(1) The absorbed dose rate has been measured only with the NPL dichromate reference transfer dosimeters [4, 5]. NPL gives an overall uncertainty of 
38 at a 958 confidence level for use of these dosimeters. The uncertainty corresponding to one standard deviation would be $1.5 \%$. Other dosimetxy methods (such as calorimetry) are being developed to improve the accuracy of the determination of this absorbed dose rate in the future.

(2) The other uncertainty factor that is different from the pool source is the timing of irradiations. There is a significant transit time when the dosimeters are entering and leaving the radiation field that is not accounted for by the irradiation timer. This transit time has been determined to effectively add 4.1 seconds to the irradiation time set on the automatic timer. This transit time was determined with an estimated uncertainty of one second at a 958 confidence level, or $0.5 \mathrm{~s}$ corresponding to one standard deviation. To minimize the effect of the transit time uncertainty, irradiation times of at least 10 minutes are used. Thus, the uncertainty in irradiation time caused by this transit time uncertainty would be $0.08 \%$ for a 10 minute irradiation.

5.4 For irradiations done with the vertical beam source, the uncertainties in absorbed dose values are given in Table 5. Some of the uncertainties have the same values as for the pool source discussed in 5.2. Those that are different are:

(1) Calibration of the exposure rate at a specific distance from the source by a standard graphite cavity ionization chamber to an estimated uncertainty of $\pm 0.7 \%$ at a $95 \%$ confidence level [14]. Thus, the uncertainty corresponding to one standard deviation would be $0.35 \%$.

(2) Conversion of the exposure rate to absorbed dose rate in water contributes an additional uncertainty of about 1.18 [15] due to factors such as the uncertainties in the values for $W$ (average energy required to produce an ion pair in air), the displacement correction factor, the ratio of energy transfer and energy absorption coefficients, and the ratio of absorbed dose to kerma. The uncertainty value is for a 958 confidence level. The value corresponding to one standard deviation would be 0.558 .

(3) The uncertainty value given in Section 3.1 .3 ( \pm 1.38 ) is obtained by combining the uncertainties from (1) and (2) in quadrature.

(4) The accuracy of timing of irradiations is determined by the uncertainty of the shutter transit time $(\approx 0.6 \mathrm{~s})$ and is estimated to be about $0.2 \mathrm{~s}$ at a 958 confidence level. The value corresponding to one standard deviation would be $0.1 \mathrm{~s}$. The minimum irradiation time that would generally be used is about $1000 \mathrm{~s}$, so the uncertainty contribution would be about 0.018 .

(5) The error in positioning the dosimeters at a location different from that of the calibrating ion chamber was estimated to be $1.0 \mathrm{~mm}$ at a $95 \%$ confidence level for a source distance of $1000 \mathrm{~mm}$. The value corresponding to one standard deviation would be $0.5 \mathrm{~mm}$ and would contribute a random uncertainty of about 0.058 .

5.5 The uncertainties in absorbed dose values assigned to the results when NBS supplies transfer standard dosimeters to a customer for irradiation in the customer's irradiation facility are given in Table 6. The transfer dosimeters are calibrated only in the pool source, so the combined uncertainties associated with irradiations with that source are listed in the first line of Table 6. Additional uncertainties (corresponding to one standard deviation) associated with the response characteristics of the transfer dosimeters are listed in the rest of Table 6 . The total uncertainty is obtained in the same manner as that discussed in 5.1 . 
Table 4

\section{UNCERTAINTIES IN ABSORBED DOSE VALUES}

FOR IRRADIATIONS WITH GAMMACELL 220

Source of Uncertainty

NPL dichromate reference

dosimeter measurement of dose rate

Source decay, half life

Timing of irradiations:

transit dose

Conversion of dose rate:

water to silicon, etc.

Attenuation corrections in

equilibrium material

Effect of dosimeter positioning

in irradiation chamber

Geometrical effects of equilibrium

material on dose rate

Source decay correction

for given date

Type A, Type B combined (in

quadrature), separately

Combined (in quadrature)

TOTAL: $3 \mathrm{X}$ Combined
Type A ( 8$)$ Type B $(z)$

(random) (other)

1.50

0.01

0.08

0.30

0.03

0.25

1.00

0.02

0.26

1.83 
Table 5

UNCERTAINTIES IN ABSORBED DOSE VALUES

FOR IRRADIATIONS WITH VERTICAL BEAM SOURCE

Source of Uncertainty

Type A ( 8 )

Type B ( 8 )

Graphite ion chamber

(random)

(other)

measurement of exposure rate

0.35

Conversion of exposure rate

0.55

to absorbed dose rate in water

0.01

Source decay, half life

0.01

Timing of irradiations:

shutter transit time

Conversion of dose rate:

0.30

water to silicon, etc.

Attenuation corrections in

0.03

equilibrium material

Effect of dosimeter positioning:

0.05

distance from source

Source decay correction

0.02

for given date

Type A, Type B combined

0.05

0.72

(in quadrature), separately

Combined (in quadrature)

0.72

TOTAL: $3 \mathrm{X}$ combined

2.2 
Table 6

UNCERTAINTIES IN ABSORBED DOSE VALUES

EMPLOYING TRANSFER STANDARD DOSIMETERS

Source of Uncertainty

Combined (in quadrature) from

Table 3

Transfer standard dosimeter

response

Dosimeter response temperature

correction

Time dependence of dosimeter

response

Effects due to differences in photon

energy spectra of sources

Type A, Type B combined (in quadrature), separately

Combined (in quadrature)

Total: $3 \mathrm{X}$ Combined
Type A ( 8 )

(random)

Type B (q)

(other)

0.34

1.05

1.00

0.50

0.50

0.50

1.06

1.36
1.72

5.2 


\section{Internal Quality Control}

6.1 Measurement assurance program (MAP) type techniques are used to ensure that calibration irradiations are performed correctly and the process is in a state of statistical control [16].

6.2 A number, $\mathrm{n}$, of check standards, in the form of calibrated radiochromic dye film dosimeters, are placed immediately adjacent to the test dosimeters during each irradiation. After irradiation, the check standard dosimeters are analyzed to produce a sequence of absorbed dose readings $c_{1}, \ldots, c_{n}$.

Thus, for a given absorbed dose level, the accepted value of the check standard is the mean of those values:

$$
A_{c}=\frac{1}{n} \sum_{i=1}^{n} c_{i}
$$

The estimated total standard deviation of the check standard dosimeter response is

$$
s_{c}=\left(\frac{1}{n-1} \sum_{i=1}^{n}\left(c_{i}-A_{c}\right)^{2}\right)^{1 / 2}
$$

The number of degrees of freedom, $\nu$, required to estimate the initial value for the actual standard deviation can be determined by choosing how close the estimate should be to the true value at a given confidence level. For example, if the estimate is to be within 208 of the true standard deviation at a 958 confidence level, then the degrees of freedom, $v=46=n-1$, or $n=47$ measurements [see sec. 2.4 of reference 14]. As the measurement assurance program progresses, additional data are obtained on the variability of the response of the check standard dosimeters, and a more reliable value for the estimated standard deviation may be computed. This is done by "pooling" the standard deviations obtained on separate occasions for the same process. If individual standard deviations are $s_{1}, \ldots, s_{k}$ with degrees of freedom $\nu_{1}, \ldots \ldots, \nu_{k}$, respectively, then the pooled standard deviation is

$$
s_{p}=\left(\frac{\nu_{1} s_{1}{ }^{2}+\ldots+\nu_{k} s_{k}{ }^{2}}{\nu_{1}+\ldots+\nu_{k}}\right)^{1 / 2}
$$

The degrees of freedom associated with $s_{\mathrm{p}}$ is $\nu=\nu_{1}+\ldots+\nu_{\mathrm{k}}$. 
6.3 Control limits may be chosen for future check standard dosimeter observations (where each observation is the mean of $\mathrm{n}=5$ readings) using the following:

$$
\begin{aligned}
& \text { Upper control limit }=A_{c}+\frac{3 s_{c}}{\sqrt{n}} \\
& \text { Lower control limit }=A_{c}-\frac{3 s_{c}}{\sqrt{n}}
\end{aligned}
$$

In this case, a safety factor of 3 was chosen; a factor of 2 is sometimes used, or for a near-normal response distribution, the appropriate percent point of the Student's $t$ distribution, $t_{\alpha / 2}(\nu)$, may be used, where $1-\alpha$ is the specified confidence level.

6.4 The control procedure applied to each future calibration depends on a test statistic, $T$, calculated from the value of the check standard, $c_{f}$ (the mean of $\mathrm{n}=5$ readings) by the following:

$$
T=\frac{\left|c_{f}-A_{c}\right|}{\frac{s_{c}}{\sqrt{n}}}
$$

If $\mathrm{T}<3$, then the process is in control. If $\mathrm{T} \geq 3$, then the process is "out of control" and remedial action is required.

6.5 Control charts are used to determine if the calibration irradiations are being performed in the proper way. Initial measurements are made to determine the mean dosimeter response and variability for each absorbed dose level. Once the dosimeter system response is adequately characterized, then control charts are drawn up that provide a baseline value for each absorbed dose level and appropriate control limits as discussed in 6.3. All subsequent readings are plotted as a function of time on these charts. All the readings should fall within the control limits except for the few that would fall outside due to pure chance (i.e., about one in a hundred for a value of $\alpha=0.01$ or the 998 confidence level). If readings fall outside the control limits more often than would be expected by pure chance, then the process is "out of control" and must be investigated and corrected.

6.6 The radiation response of the check standard dosimeter batch may change (drift) slowly with time. An "out of control" situation on the control chart may indicate such a drift in response. In that case, it is necessary to completely characterize the batch response again as was done initially in setting up the control chart.

6.7 Quality control procedures are used in other areas such as data reduction and report generation. All irradiation data, such as source decay corrections and calculated irradiation times, are double-checked for accuracy. An experienced, highly-trained technician performs all calibration irradiations and analysis of dosimeters. Senior scientific staff review all results and 
check all calibration reports. The condition of each group of test dosimeters to be irradiated is evaluated when they are received to ensure they are of high quality. Any unusual condition or appearance is checked by consulting with the requesting customer before proceeding. Checks of the performance of the various analytical instruments used are done on a periodic basis as described in Section 3. Plans are underway to further automate the data handling, such as automatic timing of the irradiation calibration.

\section{Safety}

7.1 Operation of these calibration services involves use of high-intensity ionizing radiation sources that have the potential to expose staff personnel to hazardous levels of radiation. NBS health physics rules and Nuclear Regulatory Commission regulations require that personnel using these sources have formal training in the correct operation and safe use of them. In some cases, tests are given after the training to verify that the personnel have understood the most important aspects of that training.

7.2 Access to all high-intensity source areas is limited to those staff with a need to use them. Doors to these areas are kept locked at all times with control maintained over the minimum number of keys available to the areas. 


\section{References}

1. Uriano, G.A. Garner, E.L. Kirby, R.K., and Reed, W.P., Editors, NBS Calibration Services Users Guide 1986-1988 Edition, NBS Special Publication 250 and Fee Schedule for SP 250, Office of Physical Measurement Services, National Bureau of Standards, Gaithersburg, MD 20899 (1986)

2. Greening, J. R., Fundamentals of Radiation Dosimetry, Chapters 5 and 6, Medical Physics Handbook 6, Adans Hilger Ltd., Bristol, U.K. (1981).

3. Petree, B., and Lamperti, P., "A Comparison of Absorbed Dose Determinations in Graphite by Cavity Ionization Measurements and by Calorimetry", J. Res . Natl. Bur. Stds., 71C, No.1, pp. 19-27 (1967).

4. Sharpe, P.H.G., "Dichromate Dosemeter Reference Service", National Physical Laboratory, U.K. (1984).

5. Sharpe, P.H.G., Barrett, J.H., and Berkley, A.M., "Acidic Aqueous Dichromate Solutions as Reference Dosimeters in the 10-40 kGy Range", Int. J. Appl. Radiat. Isot., 36, pp. 647-652 (1985).

6. McLaughlin, W. L., Jarrett, R. D., Sr., and Olejnik, T. A., "Dosimetry", Chapter 8 in Preservation of Food by Ionizing Radiation, Vol. I, Josephson, E. S., and Peterson, M. S., Eds., CRC Press, Boca Raton, FL, pp. $189-245$ (1982).

7. Levine, H., McLaughlin, W. L., and Miller, A., "Temperature and Humidity Effects on the Gamma-Ray Response and Stability of Plastic and Dyed Plastic Dosimeters", Radiat. Phys. Chem., 14, pp. 551-574 (1979).

8. Kaarls, R., "Report of the BIPM Working Group on the Statement of Uncertainties", 1st meeting, 21-23 Oct. 1980.

9. Giacomo, P., "News From the BIPM", Metrologia, 17, pp. 66-74 (1981).

10. Ku, H.H., "Notes on the Use of Propagation of Error Formulas", Precision Measurement and Calibration, NBS Special Publication 300-Vol.1, pp. 331-341 (1969).

11. NCRP Report No. 58, 2nd Ed., "A Handbook of Radioactivity Measurements Procedures", National Council on Radiation Protection and Measurements, Bethesda, MD (1985).

12. Hubbell, J.H., "Photon Mass Attenuation and Energy-absorption Coefficients from $1 \mathrm{keV}$ to $20 \mathrm{MeV",} \mathrm{Int.} \mathrm{J.} \mathrm{Appl.} \mathrm{Radiat.} \mathrm{Isot.,} \mathrm{33,} \mathrm{pp.} \mathrm{1269-1290} \mathrm{(1982).}$ 
13. McLaughlin, W.L., "A National Standardization Programme for High-Dose Measurements", High-Dose Measurements in Industrial Radiation Processing, IAEA Tech. Report No. 205, IAEA, Vienna, pp. 17-32 (1981).

14. Loftus, T.P., and Weaver, J.T., "Standardization of ${ }^{60} \mathrm{Co}$ and ${ }^{137} \mathrm{Cs}$ GammaRay Beams in Terms of Exposure", J. Res. Natl. Bur. Stds., 78A, No.4, pp. 465 476 (1974).

15. ICRU Report 14 "Radiation Dosimetry: X Rays and Gamma Rays with Maximum Photon Energies Between 0.6 and $50 \mathrm{MeV}$ ", Int. Com. on Radiat. Units and Measurements, Bethesda, MD (1969).

16. Belanger, B. Measurement Assurance Programs Part I: General Introduction, and Croarkin, C., Part II: Development and Implementation, National Bureau of Standards Special Publication 676I and 676II (1984).

17. Natrella, M.G., Experimental Statistics, NBS Handbook 91 (1963). 



\section{REPORT OF CALIBRATION}

Test $536 / 111111-86$

NBS DB $100 / 100$

$X R G-322$

December 26,1985

$$
\text { of }
$$

Far West Technology, Inc. Type 60-00 Radiochromic Dosimeters

$$
\text { for }
$$

Kilorad Corporation

89 Irradiator Avenue

Moline, IL 60609

Attention: Jeffrey Doe Ref.P.0. No.: 111

Far West Technology radiochromic dosimeters, type 60-00, supplled by Kilorad Corporation, were frradiated, ten at each dose, under controlled conditions using gamma radiation from a standard 60 Co source. During Irradiation the dosimeters were held between $5.0-\mathrm{mm}$ thick blocks of polystyrene, which were sealed inside polyethylene packets. The relative humidity at the time of sealing was $56 \%$. The temperature during irradiation was $24^{\circ} \mathrm{C}$. The dates of frradiation and values of absorbed dose were as follows:

\begin{tabular}{cccc} 
Dosimeter No. & Date of Irradiation & $\begin{array}{c}\text { Absorbed Dose in Water } \\
(\mathrm{kGy})^{*}\end{array}$ \\
\hline $101-110$ & 19 Dec. 1985 & 10.0 & 1.00 \\
$111-120$ & 20 Dec. 1985 & 15.0 & 1.50 \\
$121-130$ & 20 Dec. 1985 & 20.0 & 2.00 \\
$131-140$ & 19 Dec. 1985 & 25.0 & 2.50 \\
$141-150$ & 23 Dec. 1985 & 30.0 & 3.00
\end{tabular}

\# KGy $=0.1 \mathrm{Mrad}$ 
Test $536 / 111111-86$

NBS DB $100 / 100$

XRG-322

December 26,1985

Page 2 of 2 pages

The attached page describes uncertaintles and related factors in high-dose calfbrations, such as the one covered by this Report of Calfbration. Any questions regarding environmental conditions, different types of materials used, and systematic uncertainties assocfated with these calfbrations can be answered by this attachment. If there are further questions, they should be directed to the first Individual named below.

Measurements were made by

Dexi G.thcken

D. G. Hocken, Calfbrations Technictan (301) $921-2201$

Approved by

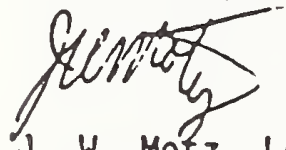

J. H. Motz, Leader

X-Ray Physics Group

For the Director

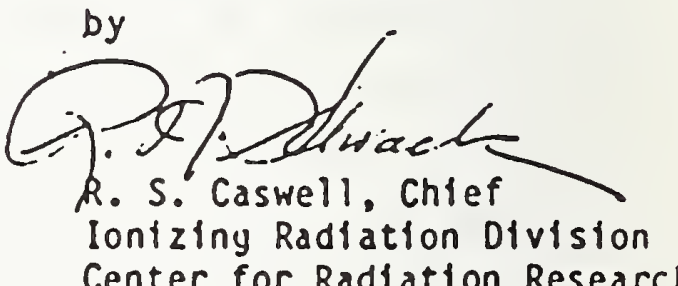


Standard High-Dose Gamma-Ray Irradiations at NBS (Estimated uncertainty: \pm 3.38 at a 998 confidence level)

The high-dose calibrations at NBS (schedule 49010S) involve the administration of ${ }^{60} \mathrm{Co}$ gamma radiation absorbed doses in certain materials (e.g., water, carbon, aluminum, silicon, polystyrene, etc.), under environmentally controlled conditions. The dose values are based on standard graphite calorimetry measurements, which are corrected by certain modifying factors (the estimated photon spectrum, tabulated weighing factors, such as radiation energy absorption and attenuation factors, and source decay factors). The irradiations are usually carried out using the NBS calibrated ${ }^{60}$ Co water-well type irradiator. The uncertainties cited above are pertinent to absorbed values specified in a given material, with the dosimeters irradiated under approximate equilibrium conditions, in the absorbed dose region of $1 \mathrm{KGy}$ and upward.

Absorbed Dose Evaluations Based on Traceability through Mailed Chemical Transfer Dosimeters (Estimated uncertainty: \pm 5.28 at a 998 confidence level)

It must be recognized by calibration users that routinely applied chemical dosimeters consisting of liquid solutions, solid films, ceramics, crystalline materials, plastics, etc., are subject to imprecision and systematic error due to environmental effects during field use, production, irradiation, and readout. Therefore, if these factors are not sufficiently known and understood, absorbed dose interpretations using such systems have reproducibility and accuracy values that are difficult to establish. Although, as indicated above, NBS in its high-dose calibrations (e.g. schedule 49010S) administers to within prescribed uncertainty limits standard absorbed doses of gamma radiation under controlled environmental conditions, the routine dosimeters for field use are subject to uneven quality control of manufacture and are occasionally susceptible to anomalous batch-to-batch or intrabatch sensitivity differences, poor reproducibility of readout results, and adverse environmental effects.

In the case of absorbed dose evaluation based on mailed transfer NBScontrolled radiochromic film dosimeters (nominal dose range $1 \times 10^{3}$ to $5 \times 10^{4} \mathrm{~Gy}$ ) that are traceable to ${ }^{60} \mathrm{Co}$ gamma-ray calibrations at NBS, the uncertainty values cited above ( $\pm 5.2 \%$ ) may be assumed as long as suitable care against environmental and other sources of systematic error is exercised.

A detailed list of the various sources of uncertainty that make up the overall uncertainties given above may be obtained by requesting such information from NBS. 

June 27,1986

FEDERAL EXPRESS PRIORITY 1

Mr. John Doe

Senior Engineer

Gamma Radiations, Inc.

123 University Avenue

Chicago, IL 60606

Dear Mr. Doe:

Reference: Your P.0. No. 12345

Enclosed are the packaged dosimeters which you requested for irradiation in your facility. There are fourteen packages: thirteen for irradiation plus one control package which should not be irradiated. Please do not open the packages at any time; they provide a controlled environment for the dosimeters. If the temperature of the packaged dosimeters is expected to increase more than $10^{\circ} \mathrm{C}$ above room temperature during irradiation, please provide information on the temperature as a function of time for the longest irradiation period. Other irradiation data, such as date and time of irradiation, length of the irradiation period, and any other pertinent information should be included with the returned dosimeters. The nominal absorbed doses received by these dosimeters should be within the range of $1 \mathrm{kGy}(0.1 \mathrm{Mrad})$ and $30 \mathrm{kGy}(3.0 \mathrm{Mrad})$. Please return the dosimeters to us as soon as the irradiations are completed so that we may get the results back to you promptly.

If you have any questions, please call me or Jim Humphreys at (301)921-2201.

Sincerely,

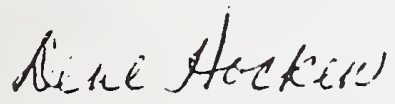

Dene G. Hocken

Calibrations Technician

X-Ray Physics Group

Center for Radiation Research

Enclosures 



\title{
REPORT OF CALIBRATION
}

of

\section{Gammacell 220 Irradiator}

for

Gammaray, Inc.

999 Cobalt Street

Miami, FL 32111

\author{
Attention: James Doe \\ Ref.P.O. No.: 32123
}

Transfer dosimetry packets, consisting of five calibrated FWT-60-00 radiochromic dosimeters (NBS Batch 144), held between 5.0 -mm thick blocks of polystyrene and sealed inside two thin polyethylene pouches (R.H. $=43 \%$ at time of sealing), were supplied to Gammaray for Irradiation in their Gammacell 220 irradiator factility. Upon their return to NBS, the dosimeters were analyzed on 9 September 1985, at two wavelengths ( $605 \mathrm{~nm}$ and $510 \mathrm{~nm}$ ) using a Cary Model 219 spectrophotometer (3.5 $\mathrm{nm}$ S.B.H.). Absorbed dose interpretations were made from a calibration of this batch of radiochromic dosimeters performed in April 1985. The results are summarized in the following table:

\begin{tabular}{cc}
$\begin{array}{c}\text { Nosimeter } \\
\text { No. }\end{array}$ & $\begin{array}{r}\text { Absorbed } \\
\left.\text { in } \mathrm{H}_{2} \mathrm{O}\right\} \\
(605 \mathrm{~nm})\end{array}$ \\
\hline $\begin{array}{c}\text { (60) } \\
696-700\end{array}$ \\
$701-705$ & (Controls) 0 \\
$706-710$ & 18.55 \\
$711-715$ & 9.00 \\
$716-720$ & 16.25 \\
$721-725$ & 11.40 \\
$726-730$ & 19.70 \\
$731-735$ & 18.90 \\
$736-740$ & 7.50 \\
$741-745$ & 23.20 \\
$746-750$ & 18.30 \\
& 19.60
\end{tabular}

$1 \mathrm{kGy}=0.1 \mathrm{Mrad}$

APPENDIX C 
Test $536 / 222222-86$

NBS DB $100 / 001$

$X R G-321$

October 10, 1985

Page 2 of 5 pages

The dosimeters were read in terms of optical absorbance before $\left(A_{0}\right)$ and after $\left(A_{j}\right)$ Irradiation, using a Cary Model 219 spectrophotometer (3.5 nm S.B.H.), at two optical wavelength settings $605 \mathrm{~nm}$ and $510 \mathrm{~nm}$. Dosimeter film thicknesses were read using a Mitutoyo Model DGS-E thickness gage. Values of increase in optical absorbance per unit thickness $\left(\Delta A / \mathrm{mm}\right.$, where $\left.\Delta A=A_{f}-A_{0}\right)$ are also included.

\begin{tabular}{|c|c|c|c|c|c|c|c|c|c|}
\hline $\begin{array}{l}\text { osimeter } \\
\text { No. }\end{array}$ & $(605 \mathrm{~nm})^{A}$ & $\{510 \mathrm{~nm})$ & $\begin{array}{l}\text { Date, } \\
\text { Tlme } \\
\text { of } A_{1} \\
\text { Reading }\end{array}$ & $(605 \mathrm{~nm})^{A}$ & $510 \mathrm{~nm})$ & $\begin{array}{l}\text { Thickness } \\
(\mathrm{mm})\end{array}$ & \multicolumn{3}{|c|}{$\begin{array}{c}\Delta A / m m \\
605 \mathrm{~nm})(510 \mathrm{~nm}) \\
\end{array}$} \\
\hline $\begin{array}{l}696 \\
697 \\
698 \\
699 \\
700\end{array}$ & $\begin{array}{l}0.1516 \\
0.1570 \\
0.1437 \\
0.1496 \\
0.1504\end{array}$ & $\begin{array}{l}0.0591 \\
0.0787 \\
0.0597 \\
0.0605 \\
0.0599\end{array}$ & $\begin{array}{c}9 / 9 / 85 \\
11: 15 \\
n \\
n\end{array}$ & $\begin{array}{l}0.1516 \\
0.1563 \\
0.1435 \\
0.1487 \\
0.1507\end{array}$ & $\begin{array}{l}0.0591 \\
0.0781 \\
0.0596 \\
0.0599 \\
0.0604\end{array}$ & $\begin{array}{l}0.050 \\
0.050 \\
0.049 \\
0.051 \\
0.051\end{array}$ & \multicolumn{3}{|c|}{ - Conerols-- } \\
\hline $\begin{array}{l}701 \\
702 \\
703 \\
704 \\
705\end{array}$ & $\begin{array}{l}0.1425 \\
0.1500 \\
0.1399 \\
0.1504 \\
0.1514\end{array}$ & $\begin{array}{l}0.0591 \\
0.0601 \\
0.0631 \\
0.0603 \\
0.0627\end{array}$ & $\begin{array}{c}9 / 9 / 85 \\
11: 25 \\
w \\
n\end{array}$ & $\begin{array}{l}1.4947 \\
1.5237 \\
1.4697 \\
1.6352 \\
1.6253\end{array}$ & $\begin{array}{l}0.2256 \\
0.2281 \\
0.2246 \\
0.2380 \\
0.2392\end{array}$ & $\begin{array}{l}0.050 \\
0.050 \\
0.051 \\
0.053 \\
0.052\end{array}$ & $\begin{array}{l}27.04 \\
27.47 \\
26.07 \\
28.01 \\
28.34\end{array}$ & $\begin{array}{l}3.330 \\
3.360 \\
3.167 \\
3.353 \\
3.394\end{array}$ & \\
\hline $\begin{array}{l}706 \\
707 \\
708 \\
709 \\
710\end{array}$ & $\begin{array}{l}0.1498 \\
0.1526 \\
0.1472 \\
0.1551 \\
0.1487\end{array}$ & $\begin{array}{l}0.0600 \\
0.0712 \\
0.0598 \\
0.0628 \\
0.0638\end{array}$ & $\begin{array}{c}9 / 9 / 85 \\
14: 35 \\
n \\
n\end{array}$ & $\begin{array}{l}0.8804 \\
0.8906 \\
0.8893 \\
0.9297 \\
0.9136\end{array}$ & $\begin{array}{l}0.1483 \\
0.1587 \\
0.1476 \\
0.1537 \\
0.1549\end{array}$ & $\begin{array}{l}0.051 \\
0.052 \\
0.050 \\
0.051 \\
0.051\end{array}$ & $\begin{array}{l}14.33 \\
14.19 \\
14.84 \\
15.19 \\
15.00\end{array}$ & $\begin{array}{l}1.731 \\
1.683 \\
1.756 \\
1.782 \\
1.786\end{array}$ & \\
\hline $\begin{array}{l}711 \\
712 \\
713 \\
714 \\
715\end{array}$ & $\begin{array}{l}0.1625 \\
0.1650 \\
0.1563 \\
0.1489 \\
0.1555\end{array}$ & $\begin{array}{l}0.0800 \\
0.0742 \\
0.0722 \\
0.0598 \\
0.0604\end{array}$ & $\begin{array}{c}9 / 9 / 85 \\
14: 45 \\
n \\
n\end{array}$ & $\begin{array}{l}1.4276 \\
1.4719 \\
1.3659 \\
1.4138 \\
1.4299\end{array}$ & $\begin{array}{l}0.2314 \\
0.2291 \\
0.2209 \\
0.2149 \\
0.2168\end{array}$ & $\begin{array}{l}0.052 \\
0.053 \\
0.052 \\
0.051 \\
0.052\end{array}$ & $\begin{array}{l}24.33 \\
24.66 \\
23.26 \\
24.80 \\
24.51\end{array}$ & $\begin{array}{l}2.912 \\
2.923 \\
2.860 \\
3.041 \\
3.008\end{array}$ & \\
\hline $\begin{array}{l}716 \\
717 \\
718 \\
719 \\
720\end{array}$ & $\begin{array}{l}0.1547 \\
0.1419 \\
0.1494 \\
0.1570 \\
0.1550\end{array}$ & $\begin{array}{l}0.0640 \\
0.0586 \\
0.0600 \\
0.0646 \\
0.0643\end{array}$ & $\begin{array}{c}9 / 9 / 85 \\
15: 00 \\
\text { w } \\
\text { n }\end{array}$ & $\begin{array}{l}1.0597 \\
1.0341 \\
1.0486 \\
1.0935 \\
1.0759\end{array}$ & $\begin{array}{l}0.1742 \\
0.1673 \\
0.1675 \\
0.1753 \\
0.1732\end{array}$ & $\begin{array}{l}0.052 \\
0.051 \\
0.050 \\
0.051 \\
0.050\end{array}$ & $\begin{array}{l}17.40 \\
17.49 \\
17.98 \\
18.36 \\
18.42\end{array}$ & $\begin{array}{l}2.119 \\
2.131 \\
2.150 \\
2.171 \\
2.178\end{array}$ & \\
\hline
\end{tabular}




\begin{tabular}{|c|c|c|c|c|c|c|c|c|c|}
\hline $\begin{array}{l}\text { osimeter } \\
\text { No. }\end{array}$ & $(605 \mathrm{~nm})^{A}$ & $9510 \mathrm{~nm})$ & $\begin{array}{l}\text { Date, } \\
\text { Tlme } \\
\text { of } A_{1} \\
\text { Reading }\end{array}$ & $(605 \mathrm{~nm})^{\mathrm{A}}$ & $(510 \mathrm{~nm})$ & $\begin{array}{l}\text { Thickness } \\
\text { (mm) }\end{array}$ & $1605 \mathrm{nn}$ & $\begin{array}{l}\Delta A / m m \\
\mathrm{~nm})(510 \mathrm{~nm}\end{array}$ & $\mathrm{nm})$ \\
\hline $\begin{array}{l}721 \\
722 \\
723 \\
724 \\
725\end{array}$ & $\begin{array}{l}0.1645 \\
0.1629 \\
0.1506 \\
0.1449 \\
0.1551\end{array}$ & $\begin{array}{l}0.0768 \\
0.0787 \\
0.0599 \\
0.0596 \\
0.0603\end{array}$ & $\begin{array}{c}9 / 9 / 85 \\
15: 10 \\
\cdots \\
\end{array}$ & $\begin{array}{l}1.6103 \\
1.5869 \\
1.6251 \\
1.6124 \\
1.6466\end{array}$ & $\begin{array}{l}0.2525 \\
0.2474 \\
0.2367 \\
0.2376 \\
0.2411\end{array}$ & $\begin{array}{l}0.052 \\
0.050 \\
0.051 \\
0.050 \\
0.051\end{array}$ & $\begin{array}{l}27.80 \\
28.48 \\
28.91 \\
29.35 \\
29.24\end{array}$ & $\begin{array}{l}3.379 \\
3.374 \\
3.467 \\
3.560 \\
3.545\end{array}$ & \\
\hline $\begin{array}{l}726 \\
727 \\
728 \\
729 \\
730\end{array}$ & $\begin{array}{l}0.1560 \\
0.1521 \\
0.1456 \\
0.1487 \\
0.1456\end{array}$ & $\begin{array}{l}0.0640 \\
0.0660 \\
0.0628 \\
0.0619 \\
0.0613\end{array}$ & $\begin{array}{c}9 / 9 / 85 \\
15: 15 \\
\cdots\end{array}$ & $\begin{array}{l}1.5462 \\
1.5674 \\
1.5400 \\
1.6037 \\
1.5786\end{array}$ & $\begin{array}{l}0.2343 \\
0.2401 \\
0.2312 \\
0.2309 \\
0.2339\end{array}$ & $\begin{array}{l}0.052 \\
0.052 \\
0.050 \\
0.051 \\
0.051\end{array}$ & $\begin{array}{l}26.73 \\
27.22 \\
27.89 \\
28.53 \\
28.10\end{array}$ & $\begin{array}{l}3.275 \\
3.348 \\
3.368 \\
3.314 \\
3.384\end{array}$ & \\
\hline $\begin{array}{l}731 \\
732 \\
733 \\
734 \\
735\end{array}$ & $\begin{array}{l}0.1531 \\
0.1536 \\
0.1467 \\
0.1533 \\
0.1526\end{array}$ & $\begin{array}{l}0.0603 \\
0.0627 \\
0.0622 \\
0.0626 \\
0.0607\end{array}$ & $\begin{array}{c}9 / 9 / 85 \\
15: 20 \\
n \\
n\end{array}$ & $\begin{array}{l}0.7674 \\
0.8066 \\
0.7493 \\
0.7802 \\
0.7690\end{array}$ & $\begin{array}{l}0.1338 \\
0.1405 \\
0.1348 \\
0.1384 \\
0.1344\end{array}$ & $\begin{array}{l}0.051 \\
0.052 \\
0.050 \\
0.051 \\
0.050\end{array}$ & $\begin{array}{l}12.04 \\
12.56 \\
12.05 \\
12.29 \\
12.33\end{array}$ & $\begin{array}{l}1.441 \\
1.496 \\
1.452 \\
1.486 \\
1.474\end{array}$ & \\
\hline $\begin{array}{l}736 \\
737 \\
738 \\
739 \\
740\end{array}$ & $\begin{array}{l}0.1512 \\
0.1516 \\
0.1477 \\
0.1508 \\
0.1469\end{array}$ & $\begin{array}{l}0.0620 \\
0.0728 \\
0.0592 \\
0.0671 \\
0.0599\end{array}$ & $\begin{array}{c}9 / 9 / 85 \\
15: 30 \\
m\end{array}$ & $\begin{array}{l}1.8718 \\
1.7489 \\
1.8657 \\
1.8354 \\
1.7632\end{array}$ & $\begin{array}{l}0.2248 \\
0.2688 \\
0.2635 \\
0.2701 \\
0.2608\end{array}$ & $\begin{array}{l}0.051 \\
0.051 \\
0.051 \\
0.050 \\
0.049\end{array}$ & $\begin{array}{l}33.74 \\
31.32 \\
33.69 \\
33.69 \\
32.99\end{array}$ & $\begin{array}{l}4.173 \\
3.843 \\
4.006 \\
4.060 \\
4.100\end{array}$ & \\
\hline $\begin{array}{l}741 \\
742 \\
743 \\
744 \\
745\end{array}$ & $\begin{array}{l}0.1614 \\
0.1516 \\
0.1581 \\
0.1471 \\
0.1464\end{array}$ & $\begin{array}{l}0.0790 \\
0.0666 \\
0.0620 \\
0.0608 \\
0.0602\end{array}$ & $\begin{array}{c}9 / 9 / 85 \\
15: 40 \\
i\end{array}$ & $\begin{array}{l}1.4965 \\
1.5044 \\
1.5585 \\
1.5296 \\
1.5344\end{array}$ & $\begin{array}{l}0.2416 \\
0.2305 \\
0.2317 \\
0.2278 \\
0.2273\end{array}$ & $\begin{array}{l}0.052 \\
0.052 \\
0.051 \\
0.050 \\
0.051\end{array}$ & $\begin{array}{l}25.68 \\
26.02 \\
27.46 \\
27.65 \\
27.22\end{array}$ & $\begin{array}{l}3.127 \\
3.152 \\
3.327 \\
3.340 \\
3.276\end{array}$ & \\
\hline $\begin{array}{l}746 \\
747 \\
748 \\
749 \\
750\end{array}$ & $\begin{array}{l}0.1501 \\
0.1518 \\
0.1538 \\
0.1488 \\
0.1467\end{array}$ & $\begin{array}{l}0.0629 \\
0.0604 \\
0.0644 \\
0.0680 \\
0.0642\end{array}$ & $\begin{array}{c}9 / 9 / 85 \\
15: 45 \\
\\
\end{array}$ & $\begin{array}{l}1.6048 \\
1.6099 \\
1.6830 \\
1.5938 \\
1.6026\end{array}$ & $\begin{array}{l}0.2418 \\
0.2355 \\
0.2481 \\
0.2435 \\
0.2380\end{array}$ & $\begin{array}{l}0.051 \\
0.050 \\
0.052 \\
0.052 \\
0.051\end{array}$ & $\begin{array}{l}28.52 \\
29.16 \\
29.41 \\
27.79 \\
28.55\end{array}$ & $\begin{array}{l}3.508 \\
3.502 \\
3.533 \\
3.375 \\
3.408\end{array}$ & \\
\hline
\end{tabular}


Test $536 / 222222-86$

NBS DB 100/001

$X R G-321$

October 10, 1985

Page 4 of 5 pages

Analysis of the dosimeter response consists of determining the mean $\Delta A / m m$ for each group of five dosimeters irradiated together and the standard deviation of each group as shown below.

\begin{tabular}{ccccc} 
Dosimeter & \multicolumn{2}{c}{ Mean $\Delta A / m m$} & \% Std. Dev.. O \\
No. & $(605 \mathrm{~nm})$ & $(510 \mathrm{~nm})$ & $(605 \mathrm{~nm})$ & $(510 \mathrm{~nm})$ \\
\hline $696-700$ & --Controls-- & - & $\cdots$ \\
$701-705$ & 27.39 & 3.321 & $3.24 \%$ & $2.70 \%$ \\
$706-710$ & 14.71 & 1.748 & $2.94 \%$ & $2.42 \%$ \\
$711-715$ & 24.31 & 2.949 & $2.52 \%$ & $2.51 \%$ \\
$716-720$ & 17.93 & 2.150 & $2.65 \%$ & $1.17 \%$ \\
$721-725$ & 28.76 & 3.465 & $2.20 \%$ & $2.54 \%$ \\
$726-730$ & 27.69 & 3.338 & $2.59 \%$ & $1.31 \%$ \\
$731-735$ & 12.25 & 1.470 & $1.73 \%$ & $1.56 \%$ \\
$736-740$ & 33.09 & 4.036 & $3.13 \%$ & $3.07 \%$ \\
$741-745$ & 26.81 & 3.244 & $3.33 \%$ & $3.05 \%$ \\
$746-750$ & 28.69 & 3.465 & $2.20 \%$ & $2.00 \%$
\end{tabular}


The attached page describes uncertainties and related factors in high-dose callbrations, such as the one covered by this Report of Calfbration. Any questions regarding environmental conditions, different types! of materlals used, and systematic uncertafnties associated with these calibrations can be answered by this attachment. If there are further questions, they should be directed to the first individual named below.

Measurements were made by

Denil (i. Hocktilu'

D. G. Hocken, Calfbrations Technictan

(30i) $921-2201$

Approved by

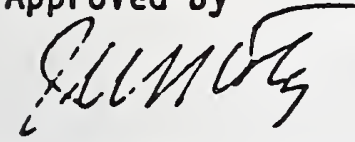

J. H. Motz, Leader

$X$-Ray Physics Group
For the Director

by

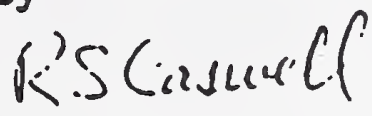

R. S. Caswell, Chief Ionizing Radiation Division Center for Radiation Research 


\section{UNCERTAINTIES AND RELATED FACTORS IN HIGH-DOSE CALIBRATIONS}

\section{Standard High-Dose Gamma-Ray Irradiations at NBS}

(Estimated uncertainty: \pm 3.38 at a 998 confidence level)

The high-dose calibrations at NBS (schedule 49010S) involve the administration of ${ }^{60} \mathrm{Co}$ gamma radiation absorbed doses in certain materials (e.g., water, carbon, aluminum, silicon, polystyrene, etc.), under environmentally controlled conditions. The dose values are based on standard graphite calorimetry measurements, which are corrected by certain modifying factors (the estimated photon spectrum, tabulated weighing factors, such as radiation energy absorption and attenuation factors, and source decay factors). The irradiations are usually carried out using the NBS ${ }^{6}{ }^{0}$ Co gamma-ray pool source. The uncertainty values cited above are for the absorbed doses given typical thin dosimeters ( 5 or less irradiated at a time) held under layers approximating electron equilibrium in a given material, in the absorbed dose region of $1 \mathrm{KGy}$ and upward.

Absorbed Dose Evaluations Based on Traceability through Mailed Chemical Transfer Dosimeters (Estimated uncertainty: \pm 5.28 at a $99 \%$ confidence level)

It must be recognized by calibration users that routinely applied chemical dosimeters consisting of liquid solutions, solid films, ceramics, crystalline materials, plastics, etc., are subject to imprecision and systematic error due to environmental effects during field use, production, irradiation, and readout. Therefore, if these factors are not sufficiently known and understood, absorbed dose interpretations using such systems have reproducibility and accuracy values that are difficult to establish. Although, as indicated above, NBS in its high-dose calibrations (e.g. schedule 49010S) administers to within prescribed uncertainty limits standard absorbed doses of gamma radiation under controlled environmental conditions, the routine dosimeters for field use are subject to uneven quality control of manufacture and are occasionally susceptible to anomalous batch-to-batch or intrabatch sensitivity differences, poor reproducibility of readout results, and adverse environmental effects.

In the case of absorbed dose evaluation based on mailed transfer NBScontrolled radiochromic film dosimeters (nominal dose range $1 \times 10^{3}$ to $5 \times 10^{4}$ Gy) that are traceable to ${ }^{60} \mathrm{Co}$ gamma-ray calibrations at NBS, the uncertainty values cited above ( $\pm 5.2 \%$ ) may be assumed as long as suitable care against environmental and other sources of systematic error is exercised.

A detailed list of the various sources of uncertainty that make up the overall uncertainties given above may be obtained by requesting such information from NBS .

Appendix C 
NBS-114A (REV. 2-8C)

U.S. DEPT. OF COMM.

BIBLIOGRAPHIC DATA

SHEET (See instructions)

1. PUBLICATION OR

REPORT NO.

NBS / SP $-250 / 11$

March 1988

4. TITLE AND SUBTITLE

NBS Measurement Services:

National Bureau of Standards High Dose Calibration Services

5. AUTHOR(S)

J.C. Humphreys, Dene Hocken, and William L. McLaughlin

6. PERFORMING ORGANIZATION (If joint or other than NBS, see instructions)

NATIONAL BUREAU OF STANDARDS

U.S. DEPARTMENT OF COMMERCE

GAITHERSBURG, MD 20899

7. ContracUGrant No.

8. Type of Report \& Period Covered

Final

9. SPONSORING ORGANIZATION NAME AND COMPLETE ADDRESS (Street, City, Stote, ZIR)

Same as item 6 .

10. SUPPLEMENTARY NOTES

Library of Congrss Catalog Card Number 88-600506

$\square$ Document describes a computer program; SF-185, FIPS Software Summary, is attached.

11. ABSTRACT (A 200-word or less factual summary of most significant information. If document includes a significant bibliography or literature survey, mention it here)

This document describes calibration services available at the National Bureau of Standards for the standardization of high absorbed dose measurements of ionizing radiation. The areas of application of such measurements include medical product sterilization, electronic device radiation hardness testing and food processing. Detailed descriptions of the NBS dosimetry procedures and uncertainty assessments are given. Measurement assurance program techniques are discussed.

12. KEY WORDS (Six to twelve entries; alphabetical order; capitalize only proper names; and separate key words by semicolons) dosimeter calibration; ionizing radiation; irradiation facilities; measurement assurance program; uncertainties

\section{AVAILABILITY}

XX Unlimited

$\square$ For Official Distribution. Do Not Release to NTIS

XX Order From Superintendent of Documents, U.S. Government IPrinting Office, Washington. D.C. 20402.

14. NO. OF

PRINTED PAGES

49

15. Price

$\square$ Order From National Technical Imformation Service (NTIS), Springfield, VA. 22161 



SP 250-1 Spectral Radlance Callbratlons 003-003-02792 \$3.50

SP 250-2 Far Ultravlolet Detector Standards 003-003-02810-0 \$4.25

SP 250-3 Radlometric Standards In the Vacuum Ultravidet 003-003-02806-1 $\$ 6.50$

SP 250-4 Fricke Dosimetry in High-Energy Electron Beams 003-003-02816-9 \$2.75

SP 250-5 Alpha-Partlcle Callbratlons SNO03-003-0283-1 $\$ 2.00$

SP 250-6 Regular Spectral Transmiltanco $003-003-02805-3 \quad \$ 3.25$

SP 250-7 Radlance Temperature Callbrations 003-003-02827-4 \$2.25

SP 250-8 Spectral Reflectance 003-003-02812-6 \$7.00

SP 250-9 Callbration of Beta-Particle-Emitting Ophthalmic Applicators $003-003-02817-7 \quad \$ 2.00$

SP 250-10 Radloactlvity Callbratlons with the " $4 \pi$ " Gamma Ionization Chamber, and Other Radloactivity Callbration Capabilities 003-003-02824-0 \$2.25

SP 250-11 Dosimetry for High-Dose Appllcations

SP 250-12 Neutron Personnel Dosimetry $003-003-02811-8 \quad \$ 2.50$

SP 250-13 Activation Foll Irradlatlon with Californlum Fission Sources

SP 250-14 Activation Foll Irradlation by Reactor Cavity Fission Sources
SP 250-15 Photometric Callbrations SN003-003-02835-5 \$4.25

SP 250-16 Calibratlon of X-Ray and Gamma-Ray Measuring Instruments

SP 250-17 The NBS Photodetector Spectral Response Callbration Transfer Program

SP 250-18 Neutron Source Strength Callbrations

SP 250-19 Callbration of Gamma-Ray-Emitting Brachytherapy Sources

SP 250-20 Spectral Irradlanco Callbrations 003-003-02829-1 \$5.50

SP 250-21 Callbration of Beta-Particle Radlation Instrumentation

SP 250-22 Platinum Resistance Thermometer Callbrations 003-003-02831-2 \$17.00

SP 250-23 Llquid-In-Glass Thermometer Callbration Service

SP 250-24 Standard Cell Callbrattons 003-003-02825-8 \$2.75

SP 250-25 Callbration Service for Inductive Voltage Dividers

SP 250-26 Phase Angle Callbrations

SP 250-27 AC-DC Difference Callbrattons

SP 250-28 Solld-State DC Voltage Standard Callbrations SN003=003-02842-8 $\$ 2.00$

SP 250-29 Traceable Frequency Callbrations SNO03-003-02844-4 \$2.25

SP 250-30 GOES Satellite TIme Code DIssemination: Description and Operation SN003-003-02845-2 \$2.75

\footnotetext{
* Those entrles containing a stock number (003-003-- ) and price can be purchased from the Superintendent of Documents, U.S. Government Printling Office, Washington, DC 20402. GPO will accept checks, money orders, VISA, and Mastercharge. For more Information, or to place an order, call (202) $783-3238$. Be sure to use the stock number In all orders. Titles without stock numbers are in preparation.
} 
U.S. Department of Commerce

National Bureau of Standards

Gaithersburg, MD 20899

Official Business

Penalty for Private Use $\$ 300$ 